NIST Technical Note 1482

METHODOLOGY FOR DEVELOPMENT OF DESIGN CRITERIA FOR JOINT HURRICANE WIND SPEED AND STORM SURGE EVENTS: PROOF OF CONCEPT

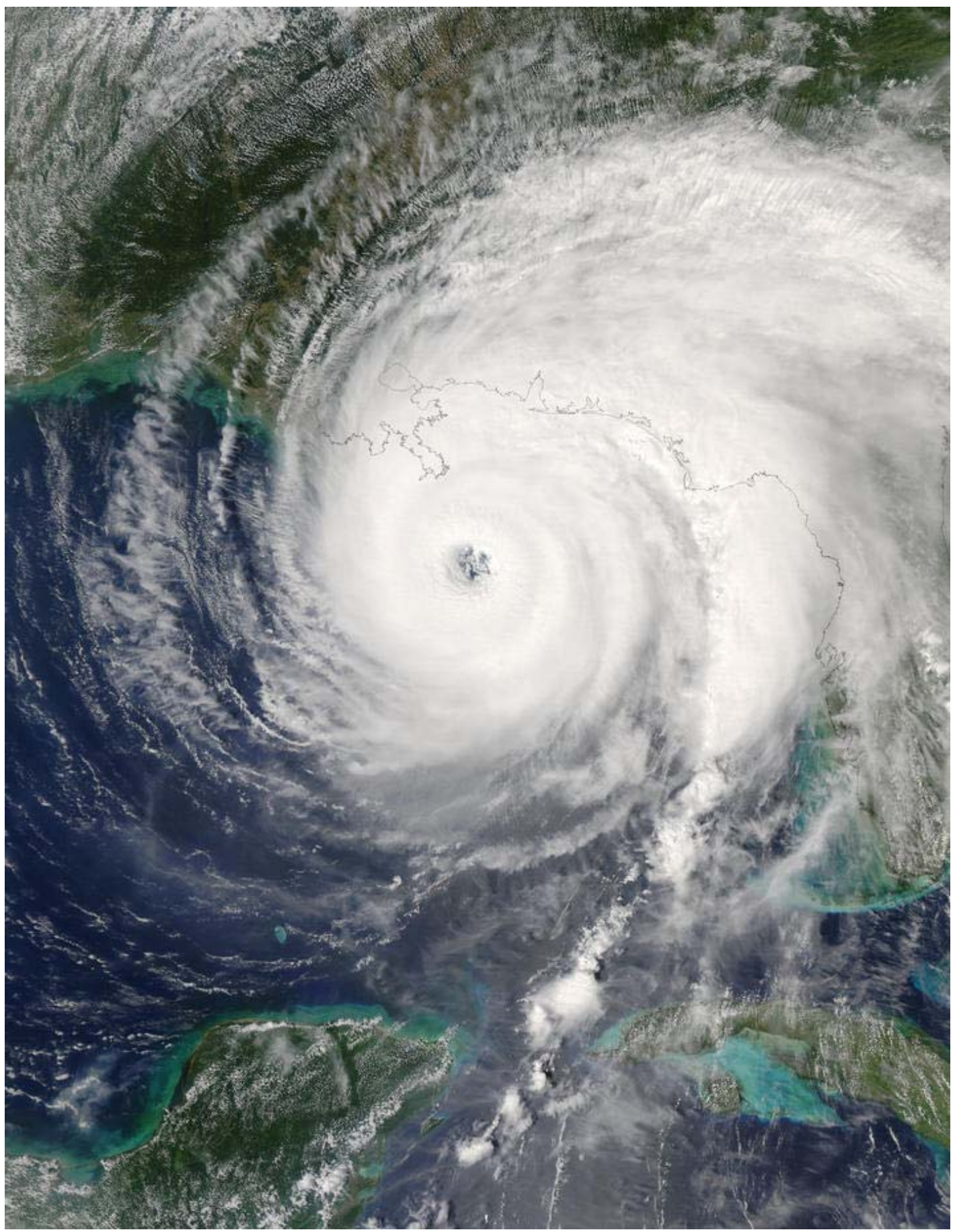





\section{METHODOLOGY FOR DEVELOPMENT OF DESIGN CRITERIA FOR JOINT HURRICANE WIND SPEED AND STORM SURGE EVENTS: PROOF OF CONCEPT}

Long T. Phan Emil Simiu Building and Fire Research Laboratory NIST

Mark A. McInerney Arthur A.Taylor Bob Glahn National Weather Service NOAA

Mark D. Powell Oceanic and Atmospheric Research

April 2007

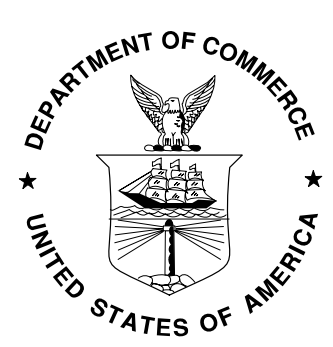

\section{U.S. DEPARTMENT OF COMMERCE} Carlos M. Gutierrez, Secretary TECHNOLOGY ADMINISTRATION Robert Cresanti, Under Secretary of Commerce for Technology NATIONAL INSTITUTE OF STANDARDS AND TECHNOLOGY 



\section{TABLE OF CONTENTS}

Acknowledgements iii

List of Acronyms and Abbreviations ...................................................................................v

List of Figures................................................................................................................................................... vii

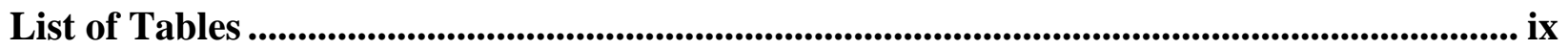

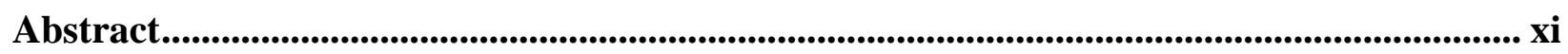

Chapter 1

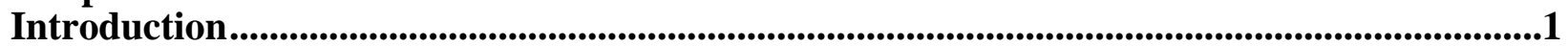

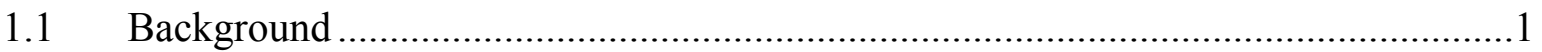

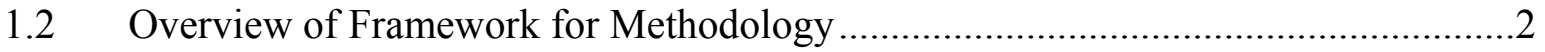

$1.3 \quad$ Objective and Scope of Report ………………….............................................

Chapter 2

Hurricane Storm Tracks, Wind Speeds, and Storm Surge Heights Simulation.........................7

$2.1 \quad$ Hurricane Storm Tracks Simulation .....................................................................

2.2 Wind Speeds and Storm Surge Heights Simulation.................................................

2.2.1 SLOSH Model and Wind Field Description................................................

2.2.2 Wind Speeds and Storm Surge Heights at Five Locations of Interest ..........12

Chapter 3

Joint Distribution and Mean Recurrence Intervals of Wind Speed and

Storm Surge Height Events...............................................................................................................15

3.1 Joint Histograms of Wind Speeds and Storm Surge Heights ..................................15

3.2 Estimated Joint And Marginal Probabilities of Exceedance......................................19

3.2.1 Joint Annual Probabilities of Exceedance …………………………................19

3.2.2 Marginal Annual Probabilities of Exceedance................................................22

3.3 Estimated Mean Recurrence Intervals of Joint Wind Speed/Storm Surge Events ...24

3.4 Alternative Methods for Estimating Probability of Exceedance and Mean

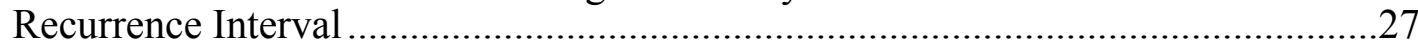

\section{Chapter 4}

Proposed Design Criterion for Structures Subjected to Combined Effect of Wind and Storm Surge.

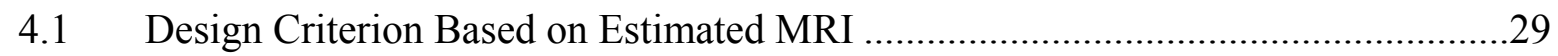

4.2 Alternative Method for Establishing Design Criterion ..............................................29 
Chapter 5

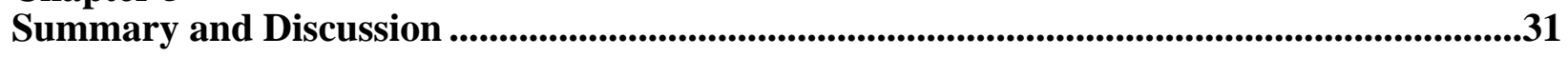

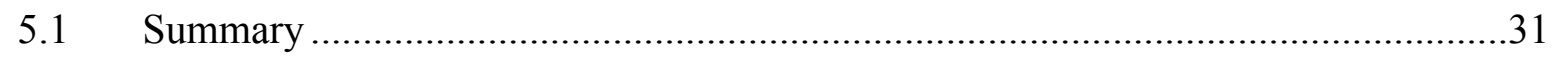

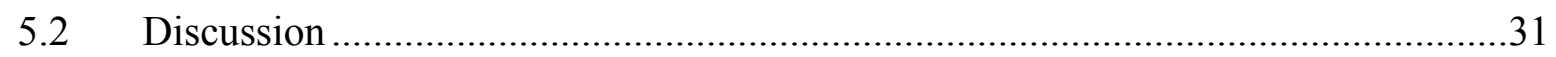

Chapter 6

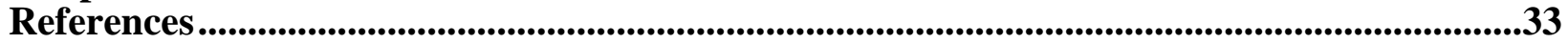

Appendix A

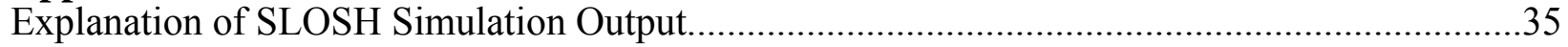

Appendix B

Typical SLOSH Simulation Output for the Port of Tampa Site

Appendix C

Alternative Methods for Estimating Joint Probability of Exceedance and Mean Recurrence Interval 


\section{ACKNOWLEDGEMENTS}

The authors gratefully acknowledge the useful contributions by Dr. Fahim Sadek of the Building and Fire Research Laboratory (BFRL), National Institute of Standard and Technology (NIST). The authors would also like to thank Dr. H.S. Lew and Mr. Stephen Cauffman of BFRL, NIST, and Dr. Will Shaffer of the National Weather Service (NWS), National Oceanic and Atmospheric Administration (NOAA) for their thoughtful and expert review of this report. 


\section{List OF ACRONYMS AND ABBREVIATIONS}

ADCIRC Advanced Circulation Model

AFB Air Force Base

AOML Atlantic Oceanographic and Meteorological Laboratory

ASCE American Society of Civil Engineers

BFRL Building and Fire Research Laboratory, NIST

ETPA Elliptical Tampa SLOSH basin identifier

FEMA Federal Emergency Management Agency

FIRM Flood Insurance Rate Map

FPHLM Florida Public Hurricane Loss Model

HRD Hurricane Research Division, OAR, NOAA

MDL Meteorological Development Laboratory, NWS, NOAA

MRI Mean Recurrence Interval

NGVD National Geodetic Vertical Datum

NHC National Hurricane Center

NIST National Institute of Standards and Technology

NOAA National Oceanic and Atmospheric Administration

NWS National Weather Service

OAR Oceanic and Atmospheric Research

PDF Probability distribution function

SLOSH Sea, Lake, and Overland Surges from Hurricanes

SPH Standard Project Hurricane 


\section{LIST OF FIGURES}

Figure 1 Location of Five Sites of Interest in the Tampa Bay Basin ..................................... 5

Figure 2 Selected Hurricane Storm Tracks from the 55,000-year FPHLM over the

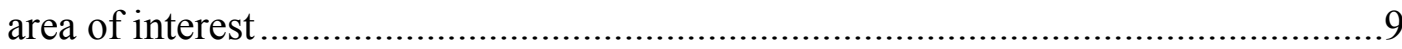

Figure 3 SLOSH Basins, Courtesy of Ethan Gibney, NHC ………………………….......10

Figure 4 Tampa Bay Basin (ETPA) highlighted time step grid points and $25 \mathrm{mi}$ track .range, Courtesy of Ethan Gibney, NHC .12

Figure 5 SLOSH Simulation showing Effect of Hurricane Track Number 17544

on the Tampa Bay Basin .14

Figure 6(a) Joint Histogram of Peak Wind Speed/Surge Height for Port of Tampa ...................16

Figure 6(b) Joint Histogram of Peak Wind Speed/Surge Height for Clearwater Beach.............17

Figure 6(c) Joint Histogram of Peak Wind Speed/Surge Height for St. Petersburg Beach .........17

Figure 6(d) Joint Histogram of Peak Wind Speed/Surge Height for MacDill AFB 18

Figure 6(e) Joint Histogram of Peak Wind Speed/Surge Height for

St. Petersburg on Tampa Bay. .18

Figure 7(a) Joint Probability of Exceedance for Port of Tampa Site .........................................20

Figure 7(b) Joint Probability of Exceedance for Clearwater Beach Site …………....................20

Figure 7(c) Joint Probability of Exceedance for St. Petersburg Beach Site ...............................21

Figure 7(d) Joint Probability of Exceedance for MacDill AFB Site...........................................21

Figure 7(e) Joint Probability of Exceedance for St. Petersburg on Tampa Bay Site..................22

Figure 8(a) Marginal Probability of Exceedance of Wind Speed for Port of Tampa Site..........23

Figure 8(b) Marginal Probability of Exceedance of Storm Surge Height for Port of Tampa Site 


\section{LIST OF TABLES}

Table 1 MRI (in Years) for Port of Tampa site..........................................................24

Table 2 MRI (in Years) for Clearwater Beach site ........................................................25

Table 3 MRI (in Years) for St. Petersburg Beach site .....................................................25

Table 4 MRI (in Years) for MacDill AFB site...............................................................26

Table 5 MRI (in Years) for St. Petersburg on Tampa Bay site..........................................26 


\section{Abstract}

This report presents proof of concept for a methodology pertaining to combined effects of | hurricane wind speed/storm surge height events. The methodology was_developed jointly by the Building and Fire Research Laboratory (BFRL) of the National Institute of Standards and Technology (NIST) and the National Weather Service (NWS) and the Oceanic and Atmospheric $\mid$ Research (OAR) of the National Oceanic and Atmospheric Administration (NOAA)._Its purpose is to develop site specific, risk-based design criteria for coastal structures subjected to the combined effects of hurricane wind speed and storm surge. The methodology utilizes an integrative, interdisciplinary approach that incorporates state-of-the-art knowledge in hurricane science, hydrology, probabilistic methods, and structural engineering needs, and involves the following steps: (1) selection of a stochastic set of hurricane storm tracks affecting the region of interest, (2) hydrodynamic simulation of the region of interest using program SLOSH and the selected storm tracks to generate time histories of wind speeds and corresponding time histories of storm surge heights at sites within the affected region, and (3) use of hurricane wind speed and storm surge height data generated in Steps (1) and (2) to develop (a) probabilistic information on joint wind speed/storm surge height events, and (b) risk-consistent structural design criteria. 


\section{Chapter 1 \\ INTRODUCTION}

\subsection{BACKGROUND}

At the present time, the design of structures in coastal high hazard area is governed by two ASCE standards. For wind and flood loading, the design is governed by ASCE 7-05 Minimum Design Loads for Buildings and Other Structures [ASCE, 2005]. For flood resistance, including high velocity wave action, the design is governed by ASCE 24 Flood Resistant Design and Construction [ASCE, 1998]. ASCE 7 provides contours of basic wind speeds for both nonhurricane and hurricane winds. Non-hurricane winds are based on a nominal 50-year mean recurrence interval (MRI) and hurricane winds are based on a longer MRI, dependent on location. The basic wind speeds provided by ASCE 7 are 3 -second gust speeds at $33 \mathrm{ft}(10 \mathrm{~m})$ above ground in open terrain with scattered obstructions having heights less than $30 \mathrm{ft}(9.1 \mathrm{~m})$ (see ASCE 7-05, Exposure C). ASCE 24 specifies mainly the elevation and foundation requirements for buildings and other structures located in flood hazard areas.

Neither ASCE 7 nor ASCE 24 addresses the combined effect of hurricane wind speed and storm surge as a design condition in a risk consistent manner. However, Table C6-1 of the ASCE 7 Commentary reproduces the Saffir/Simpson (S/S) Hurricane Scale, which describes five categories of hurricanes and the respective sustained wind speeds (1-minute average at $33 \mathrm{ft}$ (10 m) elevation) and general storm surge heights (http://www.nhc.noaa.gov/aboutsshs.shtml). (Note that, whereas the S/S scale as listed by NOAA does not specify the terrain exposure associated with the wind speeds, Table C6-1 of the ASCE 7 Commentary assumes open water exposure.) Table C6-2 of the ASCE 7 Commentary provides 3-s peak gust speeds at $33 \mathrm{ft}(10 \mathrm{~m})$ elevation over open terrain estimated to be equivalent to the 1- min speeds over open water listed in the S/S scale. Both the National Hurricane Center (NHC) and ASCE 7 stress that: "Wind speed is the determining factor used in categorizing the hurricane," with the NHC adding "as storm surge values are highly dependent on the slope of the continental shelf and the shape of the coastline in the landfall region." Although the S/S Hurricane Scale is widely used by hurricane forecasters, the news media, and local and federal agencies responsible for evacuation planning, its use for engineering design is limited by the difficulty of relating it to well-defined design criteria that account for both wind speed and storm surge height.

Special design criteria that consider the combined effect of wind speed and storm surge have been developed and used in the past for special structures. The New Orleans flood protection system was designed on the basis of such design criteria requiring that it resist the loads inherent in the Standard Project Hurricane (SPH). The SPH was developed in 1957 based on an analysis of past hurricanes of record (from 1900 to 1956) and is defined as the most severe hurricane that is considered reasonably characteristic of a region. For the New Orleans, Mississippi region, the SPH has the following characteristics: a specified central barometric pressure of 27.6 in (935 mb) of mercury, a peripheral pressure of $29.92 \mathrm{in}(1013 \mathrm{mb})$ of mercury, a maximum sustained wind speed of $110 \mathrm{mph}(49 \mathrm{~m} / \mathrm{s})$ (at $30 \mathrm{ft}(9.1 \mathrm{~m})$ elevation), a radius of maximum winds of $30 \mathrm{mi}(48 \mathrm{~km})$, a storm surge of up to $12 \mathrm{ft}(3.65 \mathrm{~m})$, and a forward speed of 
$15 \mathrm{mph}(6.7 \mathrm{~m} / \mathrm{s})$. The level of risk inherent in the SPH is not known. However, Hurricane Katrina, with estimated maximum sustained wind speeds of approximately $125 \mathrm{mph}(55.9 \mathrm{~m} / \mathrm{s}$, consistent with a category 3 hurricane on the S/S Hurricane Scale) and maximum storm surge heights of approximately $28 \mathrm{ft}(8.5 \mathrm{~m})$ (9 $\mathrm{ft}$ to $10 \mathrm{ft}$ ( $2.7 \mathrm{~m}$ to $3.0 \mathrm{~m})$ estimated for New Orleans) [NIST Technical Note 1476, 2006], clearly showed that (1) actual storm surge heights can substantially exceed the heights listed in the S/S scale for a given hurricane category, and (2) the $\mathrm{SPH}$ is inadequate as a design criterion for protection against such combination of wind speed and storm surge height event as Hurricane Katrina.

Thus, at present there is a lack of risk-based design criteria for the design of buildings and other structures in coastal, hurricane-prone regions that are subjected to the combined effect of wind speed and storm surge. Such risk-based design criteria should be developed (1) by accounting for annual probabilities of exceedance of joint wind speed/storm surge events, and (2) by considering the effects of topography and bathymetry at the sites of interest, as the storm surge at any specific location is highly dependent upon these factors. In this report, we describe a methodology, developed as part of the joint effort between the Building and Fire Research Laboratory (BFRL) of the National Institute of Standards and Technology (NIST), and the National Weather Service (NWS) and the Oceanic and Atmospheric Research (OAR) of the National Oceanic and Atmospheric Administration (NOAA), for use in establishing risk-based design criteria for structures subjected to the combined effect of wind speeds and storm surges. The methodology utilizes an integrative, interdisciplinary approach that incorporates state-of-theart knowledge and tools in hurricane science, hydrology, probabilistic methods, and structural engineering needs.

\subsection{OVERVIEW OF FRAMEWORK FOR METHODOLOGY}

The design criteria for coastal structures subjected to the combined effect of wind speed and storm surge will account for probabilities of exceedance of the joint wind speed/storm surge height events. These joint probabilities are site-dependent owing to differences in topography and bathymetry of the sites and to differences between the respective local hurricane wind climates. In addition, the probabilities may be expected to change owing to the evolution of coastal basins in time. Thus to calculate the probabilities of exceedance for any specific sites, it is necessary to have not only a stochastic set of hurricane storm tracks that would affect the sites of interest in a significant way from a structural engineering point of view, but also up-to-date information regarding the topography and bathymetry of the areas that contain the sites of interest. In general, the methodology for developing the design criteria for joint wind speed/storm surge events involves the simulation and selection of a stochastic set of hurricane storm tracks, integration of the selected storm tracks into a hydrodynamic simulation model to generate time histories of wind speeds and corresponding time histories of storm surge heights at a site, and the application of probabilistic methods to develop joint probabilities of exceedance

and mean recurrence intervals for wind speed/storm surge height events. The following steps outline in more detail the framework of this methodology: 


\section{Step 1: $\quad$ Simulation and selection of hurricane storm tracks.}

In this step, a stochastic set of hurricane storm tracks is generated from a 55,000-year simulation of the Florida Public Hurricane Loss Model (FPHLM), Version 1.0 [Powell et al., 2005]. Each hurricane is characterized by a set of climatological parameters, including the difference between atmospheric pressures at the hurricane's periphery and center, the radius of maximum wind, and its track. The hurricanes that are deemed capable of causing significant property damage in the area containing the site of interest (i.e., are significant from a structural engineering viewpoint) are selected using the threat area concept. The detailed description of this step is provided in Chapter 2.

Step 2: $\quad$ Hydrodynamic simulation to generate time histories of wind speeds and storm surge heights.

In this step, time histories of wind speeds and storm surge heights at a site are generated using a numerical-dynamic, tropical storm surge model called SLOSH (Sea, Lake, and Overland Surges from Hurricanes) [NOAA Technical Report NWS 48, 1992]. The selected hurricanes in step 1 are used to prescribe the environmental conditions in the SLOSH simulation. In addition to the time histories of wind speeds and storm surge heights, SLOSH simulation will also generate time histories of wind direction to allow for consideration of wind directionality. In this report the time histories are saved at a 5 min interval. This interval is sufficiently small so that no significant wind speed peaks are likely to be missed, yet not so small as to cause an unduly large amount of data to be generated. The detailed description of this step is also provided in Chapter 2 of this report.

With regard to SLOSH, it should be noted that NOAA uses SLOSH to conduct real-time forecasts of potential storm surge from approaching hurricanes and includes these forecasts in periodic hurricane advisories. For hurricane Katrina, NOAA, in their advisories prior to landfall, predicted based on SLOSH simulation "coastal storm surge flooding of 18 to $22 \mathrm{ft}$ above normal tide levels... locally as high as $28 \mathrm{ft}$ along with large and dangerous battering waves...can be expected near and to the east of where the center makes landfall." (Advisory number 24 4PM CDT August 28, 2005), and "storm surge flooding of 10 to $15 \mathrm{ft}$ near the tops of the levees is possible in the greater New Orleans area." (Advisory number 26B 8AM CDT August 29, 2005). These predictions using SLOSH are consistent with storm surge heights observed for hurricane Katrina [see, e.g., NIST Technical Note 1476, 2006].

Step 3: $\quad$ Use of hurricane wind speed and storm surge height data generated in Steps (1) and (2) to develop (a) probabilistic information on joint wind speed/storm surge height events, and (b) risk-consistent structural design criteria.

In this step, joint histograms of wind speeds and storm surge heights are developed using the simulated time histories of the wind speeds and storm surge heights obtained in Steps (1) and (2). The joint histograms, and the historically-based mean annual hurricane arrival rate at a site of interest, are then used to estimate probabilities of exceedance of yearly events associated with the wind speed and storm surge height at the site and corresponding MRIs. The applicability of these probabilities to the development of risk-consistent structural design criteria for the 
combined effect of wind speed and storm surge is then considered_(Chapter 3), and a simple and probabilistically rigorous approach to developing such criteria is presented (Chapter 4).

\subsection{OBJECTIVE AND SCOPE OF REPORT}

The objective of this report, which is the first report in this joint NIST-NOAA effort, is to demonstrate proof of concept for the development of an integrative methodology for use in establishing risk-based design criteria for the combined effect of wind speeds and storm surge heights. As a proof of concept, the methodology is based on the consideration of wind speeds regardless of their direction. Effect of wind directionality on wind speeds will be considered in the subsequent phase of this work. Note that wind direction is already accounted for in the storm surge calculation.

In addition, even though at present SLOSH models of coastal basins for the entire Gulf and Atlantic coasts are available for use in the hydrodynamic simulations required in step 2, the historical hurricane storm tracks necessary for characterizing the storm environments in step 1 are only available for the State of Florida through the 55,000-year simulation Florida Public Hurricane Loss Model (FPHLM, Version 1.0). The scope of this proof of concept phase is limited to five specific locations in the Tampa Bay area. These locations were selected because they are located in a populated area with substantial construction and are close to the coast and thus vulnerable to the combined effect of wind speed and storm surge. Figure 1 shows the five locations of interest in the Tampa Bay area. These include:

\begin{tabular}{|l|l|}
\hline Site & Lattitude/Longitude \\
\hline 1. Port of Tampa & $\mathrm{N} 27.949 / \mathrm{W} 82.445$ \\
\hline 2. Clearwater Beach & $\mathrm{N} 27.977 / \mathrm{W} 82.829$ \\
\hline 3. St. Petersburg Beach & $\mathrm{N} 27.726 / \mathrm{W} 82.744$ \\
\hline 4. St. Petersburg on Tampa Bay & $\mathrm{N} 27.754 / \mathrm{W} 82.631$ \\
\hline 5. MacDill Air Force Base & $\mathrm{N} 27.851 / \mathrm{W} 82.510$ \\
\hline
\end{tabular}

As explained in Section 2.2.1, SLOSH operates on a grid, and surge is calculated for grid cells on the order of a kilometer in size in each direction. Therefore, all results in this report pertain to calculations made on that basis. While the specific points in the table above are given to exact latitude and longitude locations, the calculated values pertain to the grid cell in which those points are located. Two of the sites, McDill AFB and St. Petersburg on Tampa Bay, are located in cells with an average elevation of 9 and $10 \mathrm{ft}$, respectively. However, the cells in which the other three points are located are closer to sea level. This difference in elevation is reflected in the results of Fig. 6. The actual elevations within a cell normally vary, the amount depending on the location. 


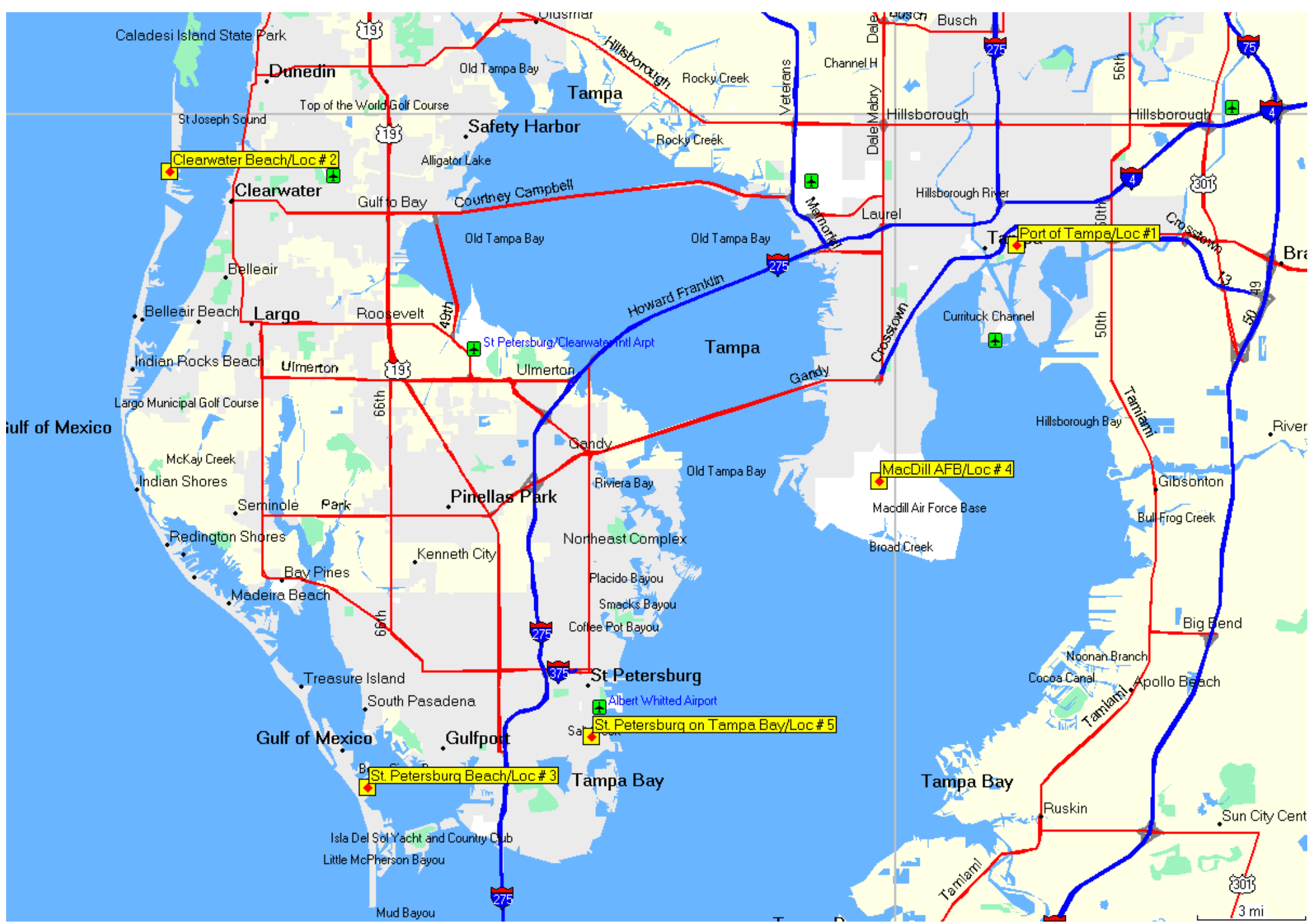

Figure 1. Locations of Five Sites of Interest in the Tampa Bay Basin 


\section{Chapter 2 \\ HURRICANE STORM TRACKS, Wind SPEEDS, AND STORM SURGE HEIGHTS SIMULATIONS}

\subsection{HURRICANE STORM TRACKS SIMULATION}

As stated in section 1.2, the Tampa Bay, Florida area was chosen as the location for this proof of concept phase of our study. A set of hurricane storm tracks that affect the Tampa Bay area was selected from the State of Florida FPHLM. To focus on storms capable of causing residential property damage in Florida, the FPHLM uses the concept of threat area to best capture the statistical characteristics of historical tropical cyclones that have affected the state. The area within $1000 \mathrm{~km}$ of a location $(26.0 \mathrm{~N}, 82.0 \mathrm{~W})$ off the southwest coast of Florida was chosen since it captures storms that can affect the panhandle, west, and northeast coasts of Florida, as well as storms that approach South Florida from the vicinity of Cuba and the Bahamas.

The threat area is divided into regions which contain the historical and seasonal characteristics of storm motion and intensity change. Genesis location, intensity, and motion for each storm are based on the geographic probability distributions of each quantity for a given time within the season. We use a stochastic approach to model the storm genesis location, track, and intensity evolution. A probability distribution function (PDF) for the initial storm position is derived from the historical "genesis" data. Here we define genesis as the time when the storm (tropical depression, tropical storm, or hurricane) forms in or first appears in the threat area. The PDF is derived for 0.5 degree latitude/longitude box regions, as well as time of season (month). A (uniform) random error term is added so that the storm may form anywhere within the 0.5 degree box.

Discrete PDFs based on historical data provide the initial and subsequent motion and intensity of the storm. A storm is simulated by repeatedly sampling from these PDFs via a Monte Carlo approach. These PDFs are derived for variable-sized regions centered at every 0.5 degree latitude and longitude in the hurricane basin. The size of these regions is determined to be that which gives a robust PDF for the quantities of interest (speed, direction, and intensity), up to some maximum size. Once the storm has been given an initial condition, its subsequent evolution is governed by sampling the PDFs for change in intensity, change in translation speed, and change in heading angle in 6 hour increments. The time step is reduced to 1 hour when the storm is close to the coastline.

The intensity parameter used in the wind model is DelP, the difference between the central minimum sea level pressure and an outer peripheral pressure (assumed to be 29.9 in of mercury $(1013 \mathrm{mb})$ in our model). Intensity change is modeled by using the observed geographic probability distribution of six-hour changes of central pressure as related to the relative intensity (Darling, 1991). Intensity change is limited so as to not exceed the maximum observed change for a particular geographic region. When a storm center crosses the coastline (landfall) the intensity change follows a pressure decay model (discussed below). If the storm 
moves back over the sea, the former intensity change model is reinstated. The PDFs for change in speed and direction depend on the current speed and direction (binned in discrete intervals), as well as geographic location ( 0.5 degree lat-lon location) and time of season (month). Storms that parallel the coast or make several landfalls can be properly simulated with this method.

Specification of the central pressure over land uses an exponential decay as a function of time after landfall developed by Vickery and Twisdale (1995). The advantage of the filling model is that it provides a starting point to invoke an intensity redevelopment for storms that exit the coastline and re-intensify over water. When a storm reemerges over water, the intensity is modeled along the track the same way it was before landfall using the decayed pressure as an initial value. The motion of the vortex is determined by the modeled storm track. The symmetric pressure field $\mathrm{p}(\mathrm{r})$ is specified by the Holland (1980) pressure profile with the central pressure specified according to the intensity modeling in concert with the storm track. A model for the Holland B pressure profile parameter was developed based on a subset of the data published by Willoughby and Rahn (2004). The radius of maximum wind at landfall is modeled as a function of latitude and minimum central barometric pressure $P_{\min }$ using a database constructed from a variety of landfall data including the NWS-38 publication (1987), and extended best track by DeMaria et al. (2002), and NOAA HRD archives.

Using the above method for simulating and selecting hurricane storm tracks affecting the point specific locations of interest in the Tampa Bay basin, a total of 19,806 hurricane storm tracks were selected. Figure 2 shows a portion of one of the storm tracks selected from the FPHLM model, hurricane track number 17526, together with its wind field entering the area of interest in the Tampa Bay basin.

\subsection{WIND SPEEDS AND STORM SURGE HEIGHTS SIMULATION}

Wind speeds and storm surge heights at the five selected locations in Tampa Bay caused by the 19,806 hurricanes are simulated using the SLOSH model. Below is a brief description of SLOSH, SLOSH basins, and the method it uses to generate wind field and associated storm surge.

\subsubsection{SLOSH Model and Wind Field Description}

SLOSH is a dynamic, two dimensional numerical model developed by the NWS to estimate tropical storm surge flooding. SLOSH works from high resolution curvilinear polar, elliptical, or hyperbolic grids separated into 41 unique basins across the Gulf of Mexico, eastern seaboard, the Bahamas, Puerto Rico, and Hawaii. Each type of grid is mapped conformally onto a Cartesian type of grid for computations, taking care to use the relevant map factors and Jacobian - See Figure 3. 


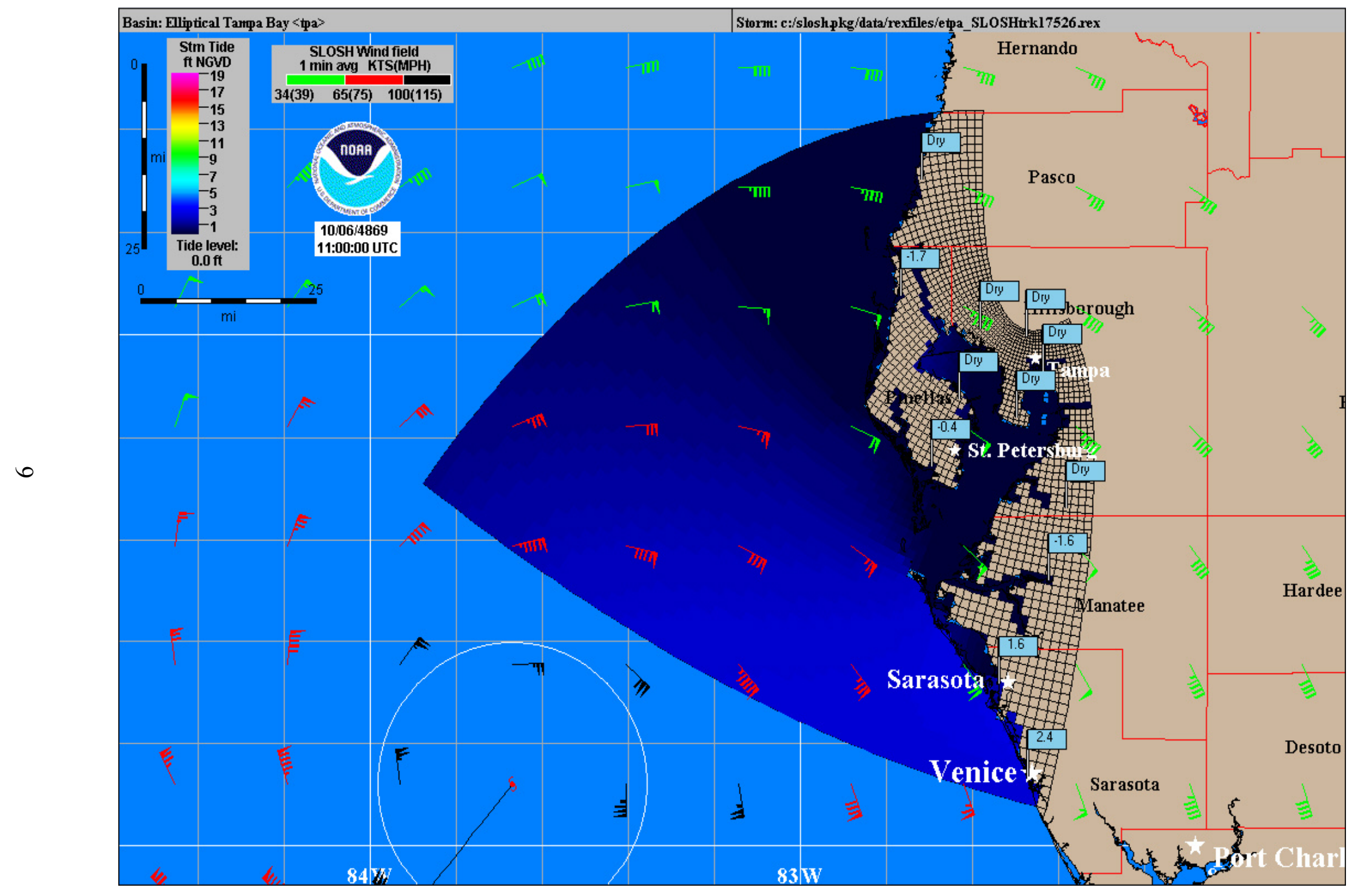

Figure 2. Selected hurricane storm track (hurricane number 17526) from the 55,000-year FPHLM over the area of interest 


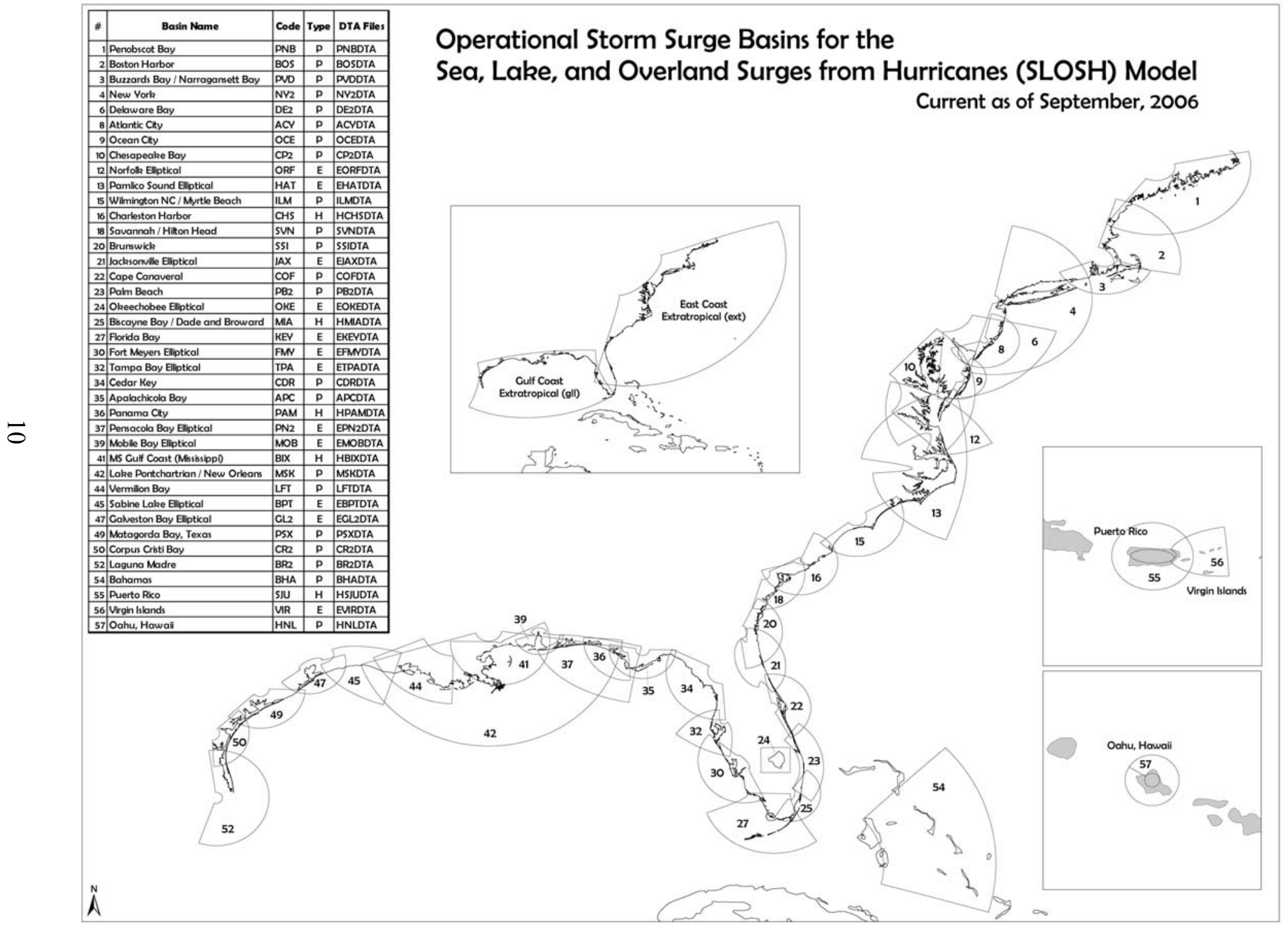

Figure 3 - SLOSH Basins, Courtesy of Ethan Gibney, NHC 
This grid-based coordinate system provides finer mesh near the pole point and becomes coarse at outer boundaries. As a result, high resolution data for areas of interest along the coast and inlet bays are available. Additionally, sub-grid elements such as channels, barriers, and rivers are modeled to improve calculated surge values during processing. Storm surge is calculated by solving shallow water equations derived from the transport equations of motion and the continuity equation based from input such as topography, bathymetry, and storm track which includes change in pressure, radius of maximum winds $\left(R_{\max }\right)$, location, wind direction and wind speed. Parameters not modeled in the SLOSH include astronomical tides, rainfall, river flow, and wind-driven waves. The basic equations solved by the SLOSH model are:

$$
\begin{gathered}
\frac{\partial U}{\partial t}=-g(D+h)\left[B_{r} \frac{\partial\left(h-h_{o}\right)}{\partial x}-B_{i} \frac{\partial\left(h-h_{o}\right)}{\partial y}\right]+f\left(A_{r} V+A_{i} U\right)+C_{r} x_{\tau}-C_{i} y_{\tau} \\
\frac{\partial V}{\partial t}=-g(D+h)\left[B_{r} \frac{\partial\left(h-h_{o}\right)}{\partial y}+B_{i} \frac{\partial\left(h-h_{o}\right)}{\partial x}\right]+f\left(A_{r} U-A_{i} V\right)+C_{r} y_{\tau}+C_{i} x_{\tau} \\
\frac{\partial h}{\partial t}=-\frac{\partial U}{\partial x}-\frac{\partial V}{\partial y},
\end{gathered}
$$

where $U$ and $V$ are the components of transport, $\mathrm{g}$ is the gravitational constant, $D$ is the depth of quiescent water related to the National Geodetic Vertical Datum (NGVD 29) established by geodetic surveys and optical levelings or transits, $h$ is the height of water above the NGVD, $h_{o}$ is the hydrostatic water height, $f$ is the Coriolis parameter, $x_{\tau}$ and $y_{\tau}$ are the components of surface stresses, and $A_{r}, A_{i}, B_{r}, B_{i}, C_{r}$, and $C_{i}$ are the bottom stress terms [Jelesnianski et al. 1992]

The surface stress, $\vec{\tau}$, is an important term in the equations of motion. Generally, the wind stress per unit mass on the sea surface is expressed as:

$$
\vec{\tau}_{(x, y, t)}=C_{D} \frac{\rho_{a}}{\rho_{w}}\left|\vec{W}_{(x, y, t)}\right| \vec{W}_{(x, y, t)}
$$

where $C_{D}$ is the drag coefficient, $\rho_{w}$ and $\rho_{a}$ are densities of water and air, and $W$ is the vector wind. The $\mathrm{z}$ coordinate of the stress term is $z=z_{s}$ where $z_{s}$ is the distance above the sea surface typically 10 meters and where meteorological wind sources retained at the surface utilize a constant pressure to be converted to $z_{s}$ [Jelesnianski et al. 1992]. Rather than the vector wind field just described, the SLOSH model utilizes a simplified parametric wind model, based on pressure and $R_{\max }$ winds, to calculate surface stresses over water that generate storm surge values for the model. One half of the hurricane's forward speed is added vectorially to the symmetric winds to provide asymmetry. Houston et al., 1999 compared SLOSH wind model fields to observation-based wind analyses from the NOAA AOML $\mathrm{H}^{*}$ Wind system and found that 
SLOSH winds were on average $14 \%$ lower than the $\mathrm{H}^{*}$ Wind analyses at locations between $.75-$ 1.5 times the radius of maximum winds. Beyond 1.5 Rmax, wind speed differences tended to be larger with cases as large as $27 \%$ lower (Hurricane Bob 1991 off Rhode Island 1991) than $\mathrm{H}^{*}$ Wind and 15\% higher than $\mathrm{H}^{*}$ Wind (Hurricane Bob 1991 off North Carolina).

\subsubsection{Wind Speeds and Storm Surge Heights at Five Locations of Interest}

The five locations of interest considered in this proof of concept phase are located within the Tampa Bay basin (ETPA), which is characterized by an elliptical/hyperbolic grid extending from Citrus County south through Sarasota county and covering approximately 252 statute miles (405 km) of coastline (Basin number 32 in Figure 3) - see Figure 4.

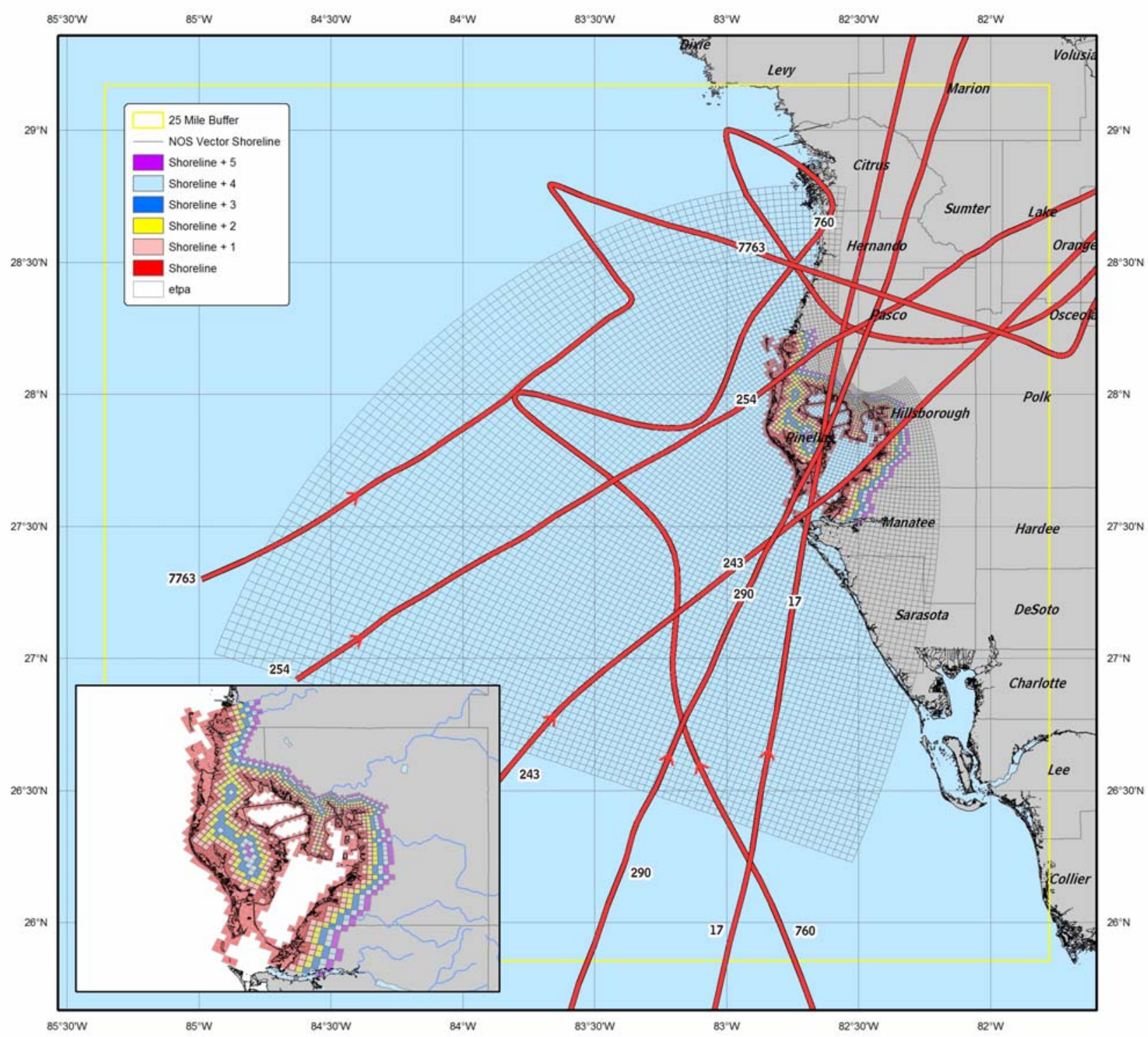

Figure 4 - Tampa Bay Basin (ETPA) highlighted time history grid points and 25 mi track range, Courtesy of Ethan Gibney, NHC 
To capture hurricane tracks from the FPHLM that affect the five locations of interest in this basin a $25 \mathrm{mi}(40 \mathrm{~km})$ buffer was established around the basin as shown in yellow in Figure 4. The total number of tracks identified to cross inside this buffer was 23,166 of the 103,000 tracks in the 55,000 year simulated track dataset. From these tracks, 19,806 tracks corresponding to hurricanes significant from a structural point of view were utilized for this proof of concept study to generate the requisite time histories of wind speeds and storm surge heights. Several of these selected tracks (hurricane tracks number 17, 243, 254, 290, 760, and 7763) are also displayed on Figure 4.

For the five locations, time histories of wind directions, wind speeds, and storm surge heights at 5 min intervals, corresponding to each of the 19,806 selected hurricane storm tracks were generated. Figure 5 shows a typical result of SLOSH simulation which indicates the effect, at one point in time, of hurricane track number 17544 on the Tampa Bay basin. Appendix A shows a typical SLOSH output for the Clearwater Beach location $(27.9767 \mathrm{~N}, 82.8366 \mathrm{~W})$. In this example, the time histories were created by the effect of hurricane storm track number 12364 generated from 55,000-year simulation for State of Florida FPHLM. 


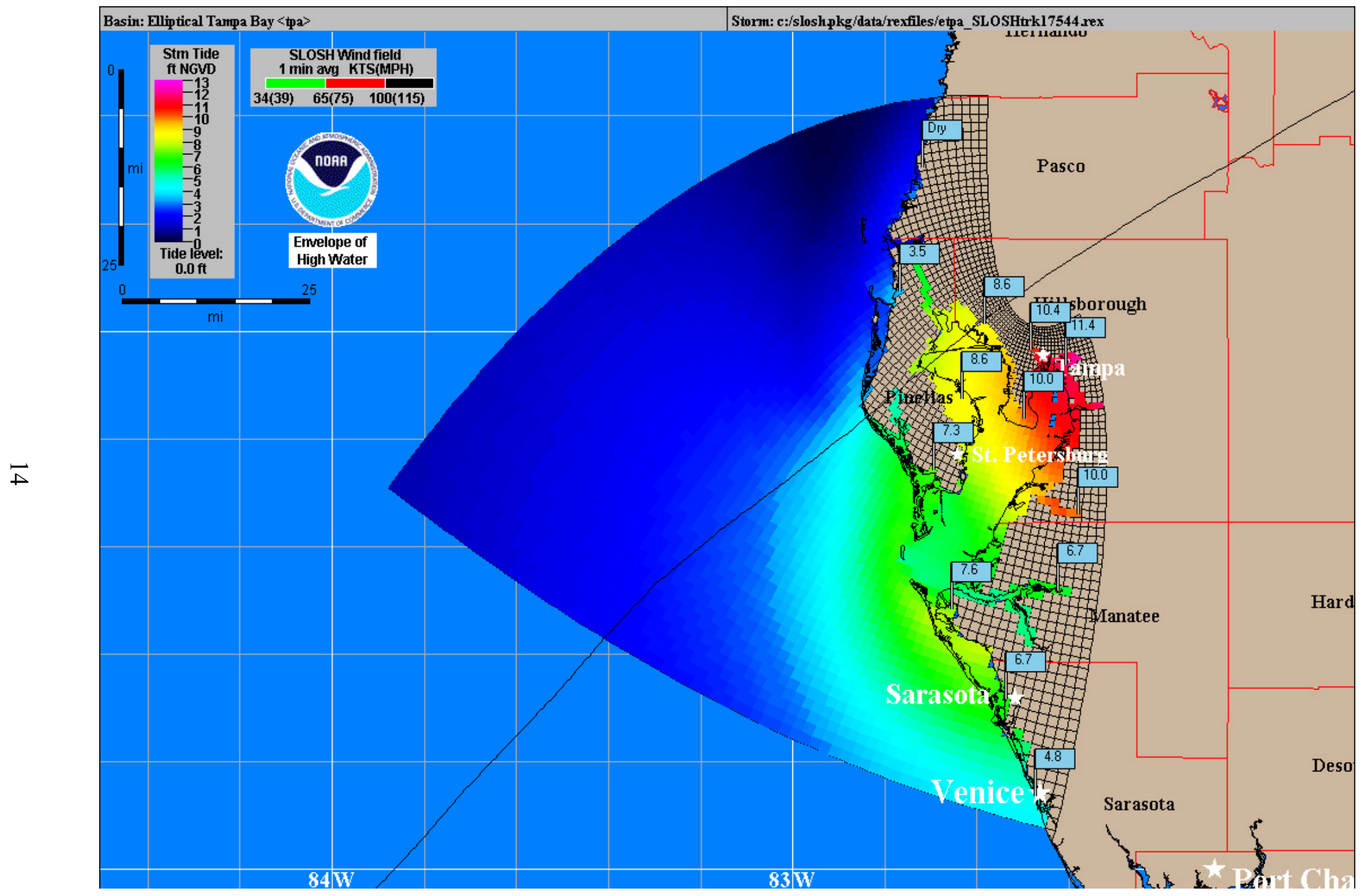

Figure 5. SLOSH Simulation showing Effect of Hurricane Track Number 17544 on the Tampa Bay Basin 


\section{Chapter 3 \\ Joint Histograms, Probabilities of EXCEEdAnCE, AND MEAN RECURRENCE INTERVALS OF WIND SPEED AND STORM SURGE HEIGHT EVENTS}

In this Chapter, the time histories of wind speeds and storm surge heights generated in step 2 of the methodology described in Chapter 2 are used to develop estimates of joint histograms and of corresponding probabilities of exceedance and mean recurrence intervals of wind speed/storm surge events.

\subsection{JOINT HISTOGRAMS OF WIND SPEEDS AND STORM SURGE HEIGHTS}

The same hurricanes are considered for all five sites listed in Chapter 2, since the distances between those sites are sufficiently small (less than $20 \mathrm{mi}(32 \mathrm{~km})$, see Figure 1). Let $n$ denote the number of simulated hurricane storm tracks being considered (in this study $n=19,806)$. For each hurricane $h_{i}(i=1,2, \ldots, n)$ hydrodynamic simulation using SLOSH yields time histories of the wind speed $v_{i j}$ and storm surge height $s_{i j}$ for all five locations $(j$ is the index that denotes the number of time intervals; the corresponding time is $t_{j}=j \Delta t$, where $\Delta t$ is a 5 -min time interval). Under the effect of the same hurricane $h_{i}$, the wind speeds $v_{i j}$ and the storm surge height $s_{i j}$ differ from site to site owing to the respective topographies and bathymetries. (As indicated in Chapter 2, for the proof of concept purposes of this report we followed the ASCE 7 Standard wherein wind speeds are specified regardless of their direction, and did not consider wind directionality.)

For hurricane track $h_{i}$, a data pair consisting of the maximum wind speed $v_{i, \max } \equiv \max _{j}\left(v_{i j}\right)$ and the maximum storm surge height $s_{i, \max } \equiv \max _{j}\left(s_{i j}\right)$ at a site can be extracted from the time histories of wind speed and storm surge height generated from the SLOSH simulation. Note that the speed $v_{i, \max }$ and the storm surge height $s_{i, \max }$ generally do not occur at the same times during the life of hurricane $h_{i}$ (for example, Hurricane Katrina's estimated maximum wind speeds of $175 \mathrm{mph}(78 \mathrm{~m} / \mathrm{s})$ was recorded 18 hours before landfall, when maximum surge heights were observed. Also, Appendix B shows results of a typical SLOSH simulation, in this case for the Port of Tampa site, where the time of peak wind speed (84 mph at $1359.50 \mathrm{~min}$ in the storm history, when the surge height is zero ( $99.9 \mathrm{ft}$ denotes a dry point)) is different from the time of peak storm surge height (peak surge height of $3.3 \mathrm{ft}$ occurred at $1564.50 \mathrm{~min}$ in the storm history.) Therefore, designing a structure or other system under the assumption that they occur simultaneously would result in conservative ${ }^{1}$ designs. For the 19,806 selected hurricanes, data pairs $v_{i, \max }, s_{i, \max }(i=1,2, \ldots, 19,806)$ can be similarly extracted for each site of interest from the results of 19,806 SLOSH simulations.

\footnotetext{
${ }^{1}$ In structural engineering terminology a design is referred to as conservative if it results in a structural safety level that exceeds minimum requirements prescribed in standard engineering practice. An unconservative design is one that results in a structural safety level that does not meet those requirements.
} 
Next, we rank order the data pairs $v_{i, \max }, s_{i, \max }(i=1,2, \ldots, 19,806)$ for each site of interest based first on decreasing values of $v_{i, \max }$ and then on decreasing values of $s_{i, \max }$. The following is an example of the data pairs of wind speed and storm surge height occurring at a site after rank ordering:

$\begin{array}{cl}\begin{array}{c}\boldsymbol{v}_{\boldsymbol{i}, \max } \\ (1-\mathrm{minute} \mathrm{m} / \mathrm{s})\end{array} & \begin{array}{l}\boldsymbol{s}_{\boldsymbol{i}, \max } \\ (\mathrm{m})\end{array} \\ 70 & 6 \\ 70 & 5.5 \\ 68 & 6 \\ 68 & 5.8 \\ 68 & 5.3 \\ 65 & 5.5 \\ 65 & 4.7 \\ 60 & 5.0 \\ 55 & 5.2 \\ 55 & 4.5 \\ \ldots & \ldots \\ \ldots & \ldots\end{array}$

Next, we construct, for each site, a joint histogram that includes the sample of the $n=19,806$ pairs of peak wind speed/storm surge height data just described. These pairs occur during the time interval $T=55,000$ years associated with the $n$ hurricanes. Figures 6(a) to 6(e) show the joint histograms of peak wind speeds/storm surge heights derived from the above procedure.

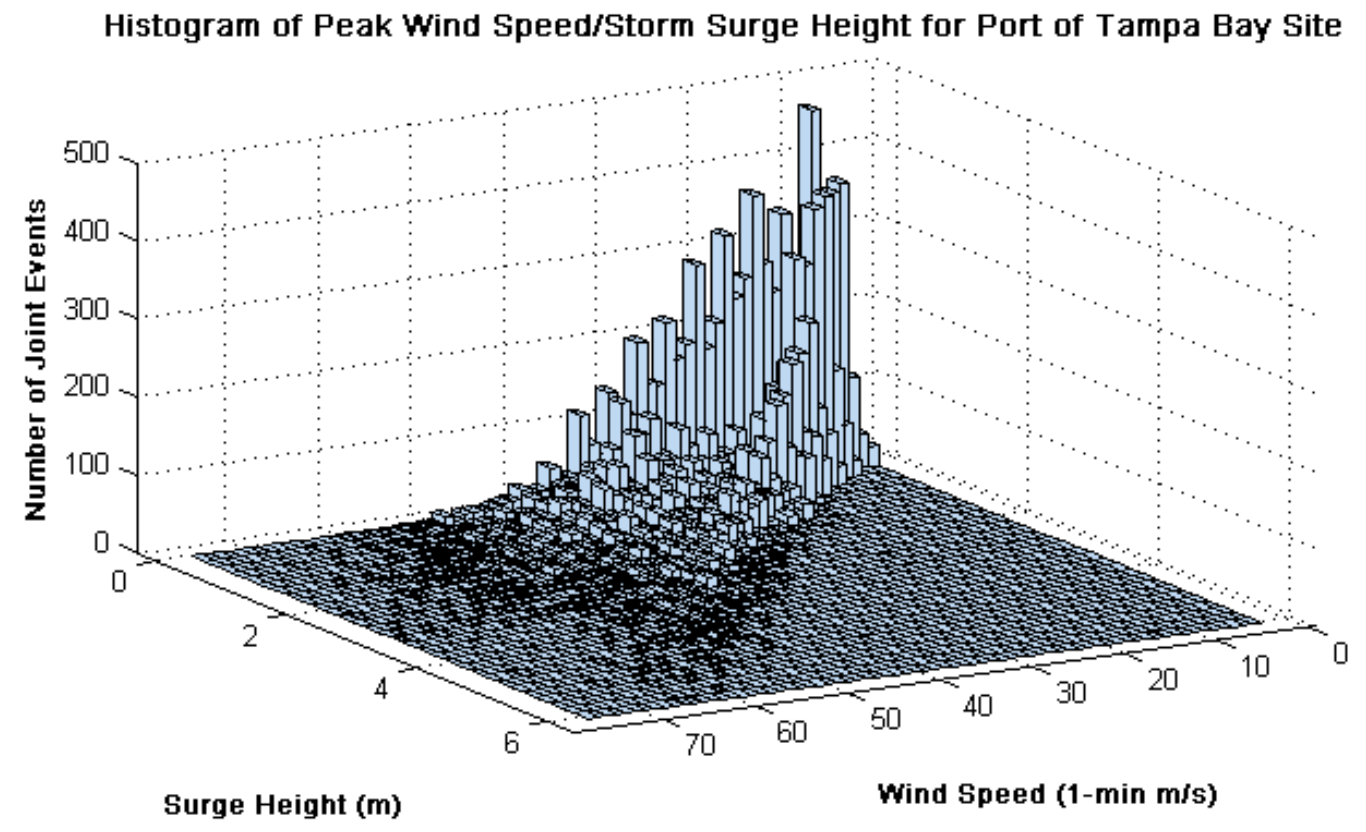

Figure 6(a) Joint Histogram of Peak Wind Speed/Surge Height for Port of Tampa 
Histogram of Peak Wind Speed/Storm Surge Height for Clearwater Beach Site

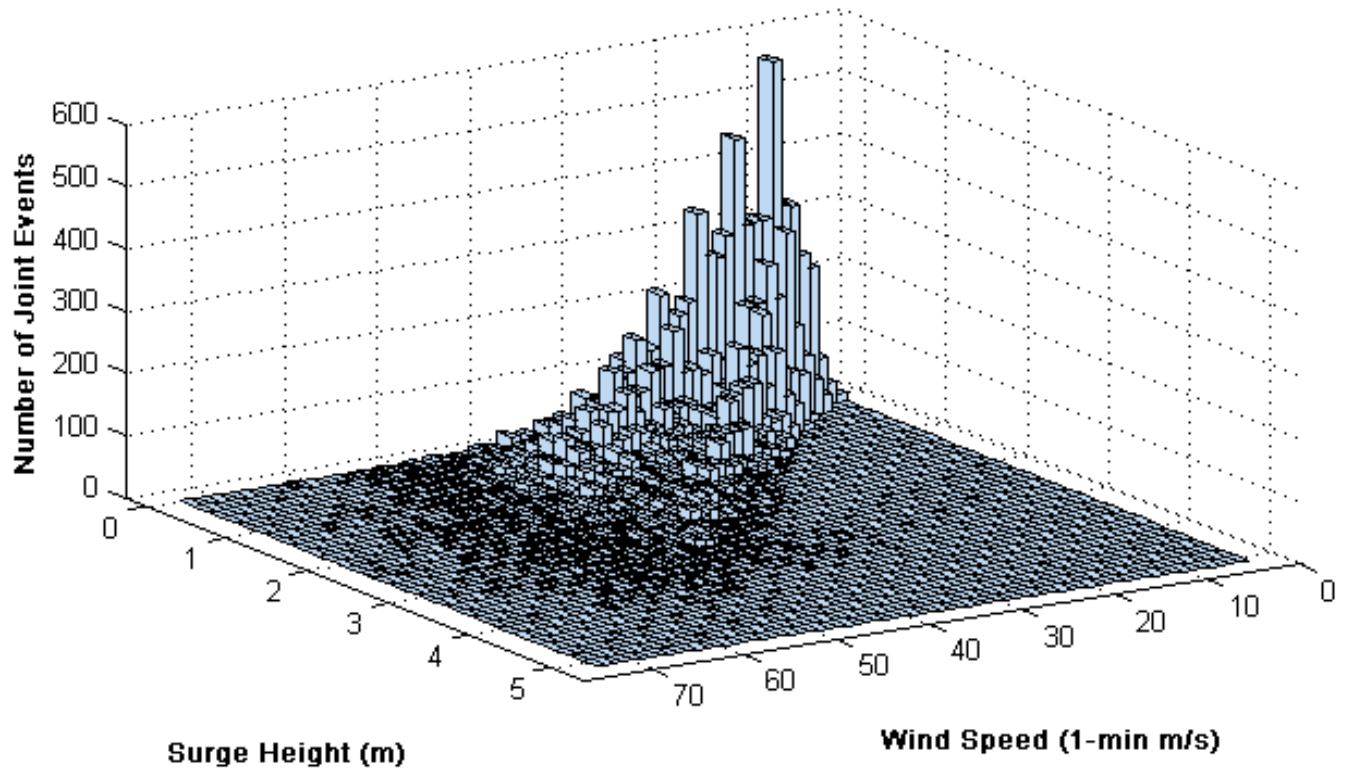

Figure 6(b) Joint Histogram of Peak Wind Speed/Surge Height for Clearwater Beach

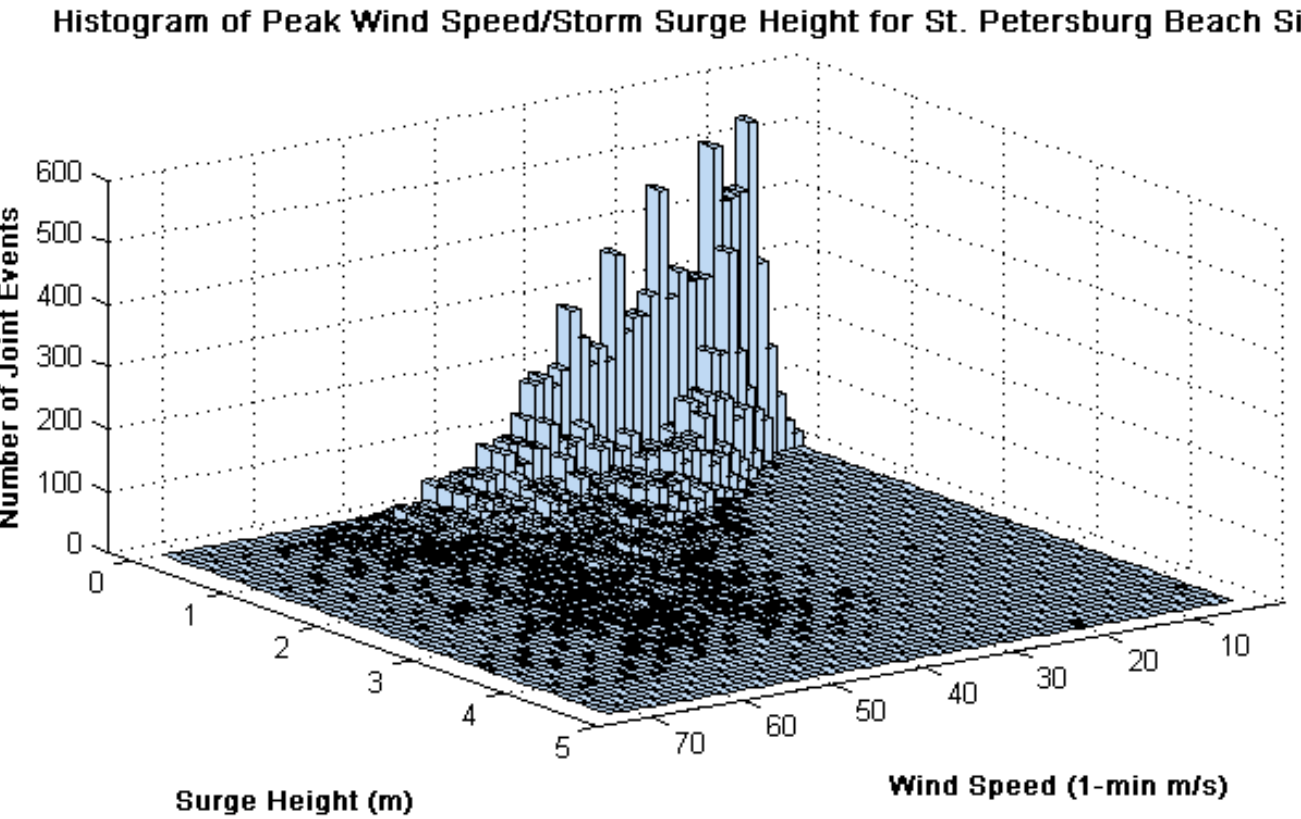

Figure 6(c) Joint Histogram of Peak Wind Speed/Surge Height for St. Petersburg Beach 
Histogram of Peak Wind Speed/Storm Surge Height for MacDill AFB Site

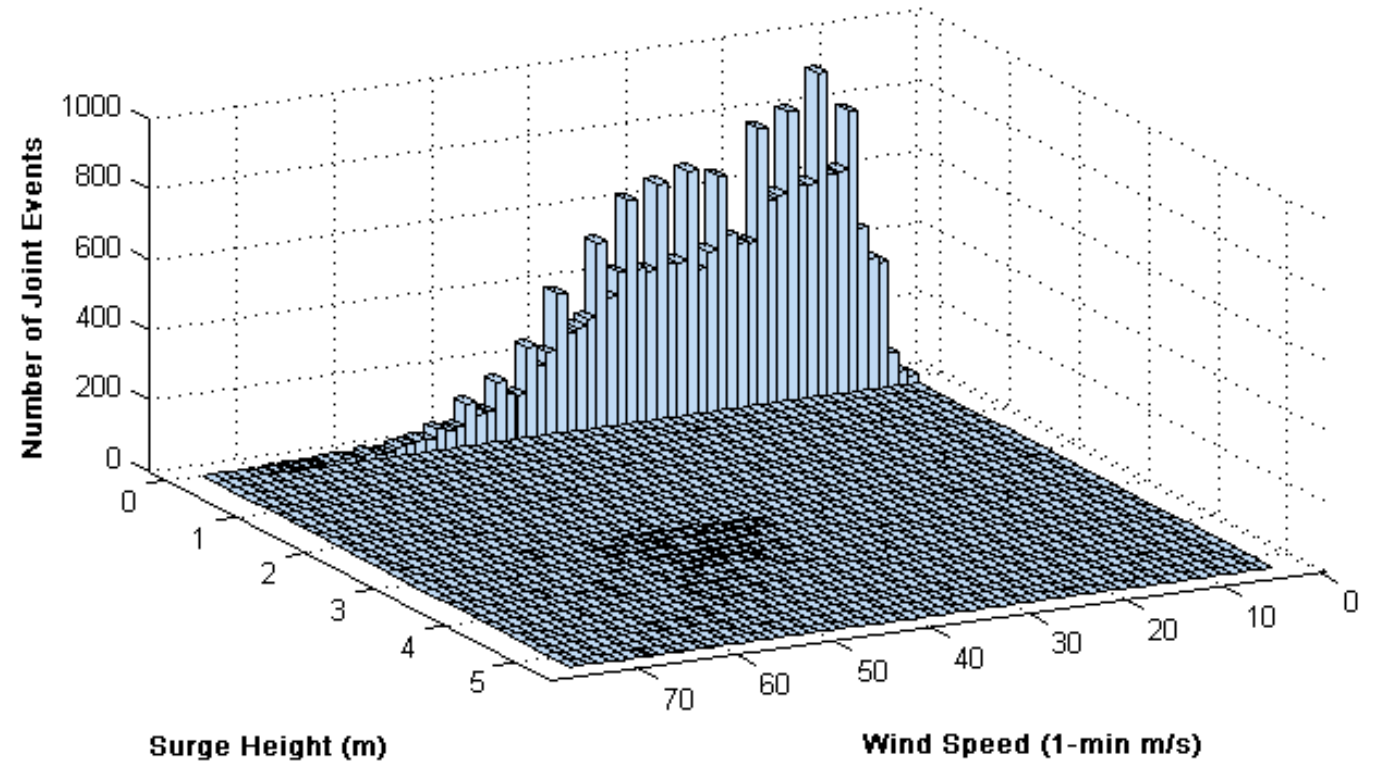

Figure 6(d) Joint Histogram of Peak Wind Speed/Surge Height for MacDill AFB

Histogram of Peak Wind Speed/Storm Surge Height for St.Petersburg on Tampa Bay Site

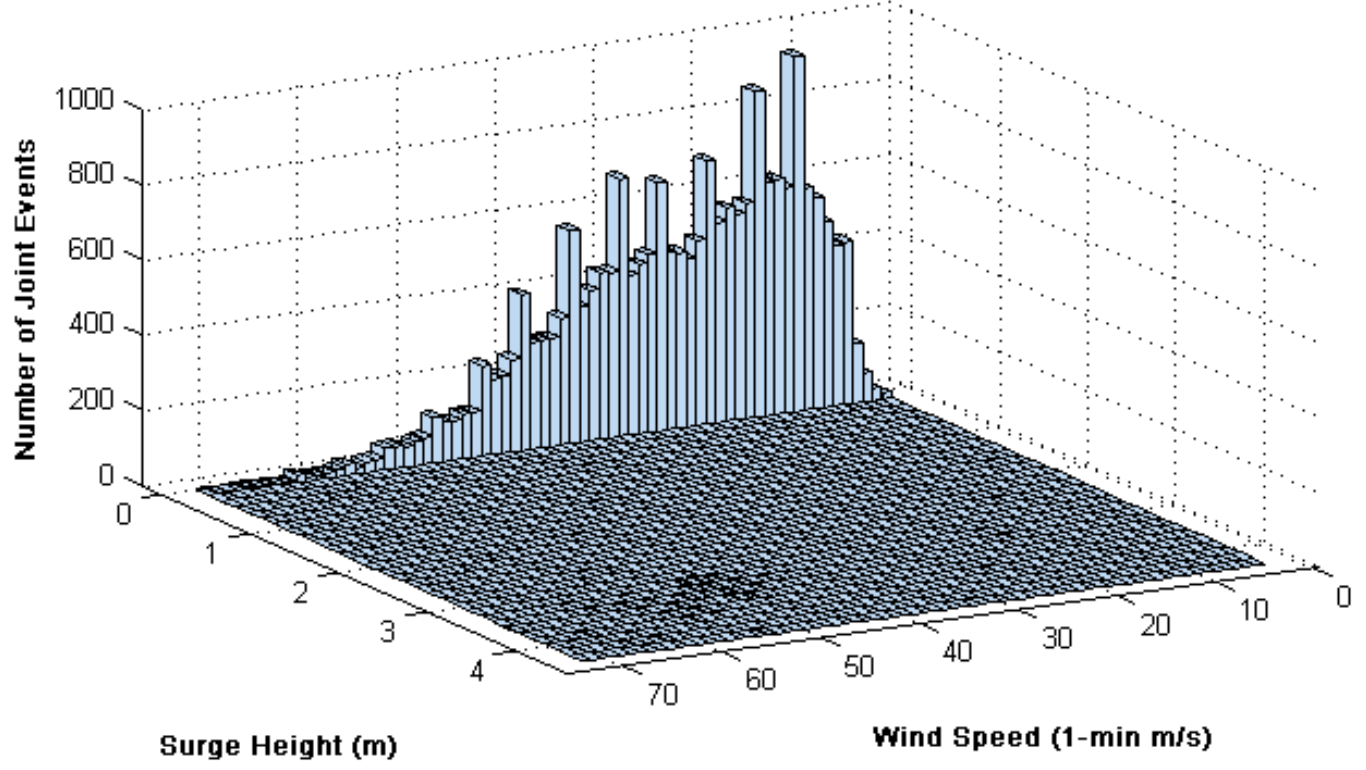

Figure 6(e) Joint Histogram of Peak Wind Speed/Surge Height for St. Petersburg on Tampa Bay 
As indicated by the respective histograms, events with relatively high wind speed and storm surge heights can be expected to occur at the Port of Tampa, Clearwater Beach, and St. Petersburg Beach sites (sites 1, 2, and 3). The joint histograms for the MacDill AFB and St. | Petersburg on Tampa Bay_sites (sites 4 and 5), however, indicate that these two sites are mainly affected by wind and not by storm surge. This may be a consequence of the local topography associated with these two sites (both have high elevations as indicated in Section 1.3.) For locations with lower elevations, even by-passing tropical storms can generate sufficient wind forcing to flood low lying areas with water levels higher than $0.5 \mathrm{~m}$ within Tampa Bay at St. Petersburg and Apollo Beach (Houston and Powell 1994).

\subsection{ESTIMATED JOINT AND MARGINAL PROBABILITIES OF EXCEEDANCE}

\subsubsection{Joint Annual Probabilities of Exceedance}

From the histograms created in Section 3.1, we next obtain an estimate of the annual probability of exceedance, denoted by $P(V>v, \mathrm{~S}>s)$, of the joint event with wind speed $V>v$ and storm surge height $S>s$, by (1) counting the number of data pairs with wind speeds greater than $v$ and storm surge heights greater than $s$ in each of the joint histograms, (2) dividing that number by the total number of data pairs, $n=19,806$, and (3) multiplying the outcome by the mean annual hurricane rate of occurrence $\lambda$, where $\lambda=n / T=19,806 / 55,000=0.3601$ hurricane/year. Plots of the estimated joint annual probability of exceedance of events $v, s$ are shown in Figures 7(a) to 7(e). Each contour plotted on the wind speed/storm surge height plane on these Figures indicates wind speeds and storm surge heights for which the estimated joint annual probabilities of exceedance has the same value.

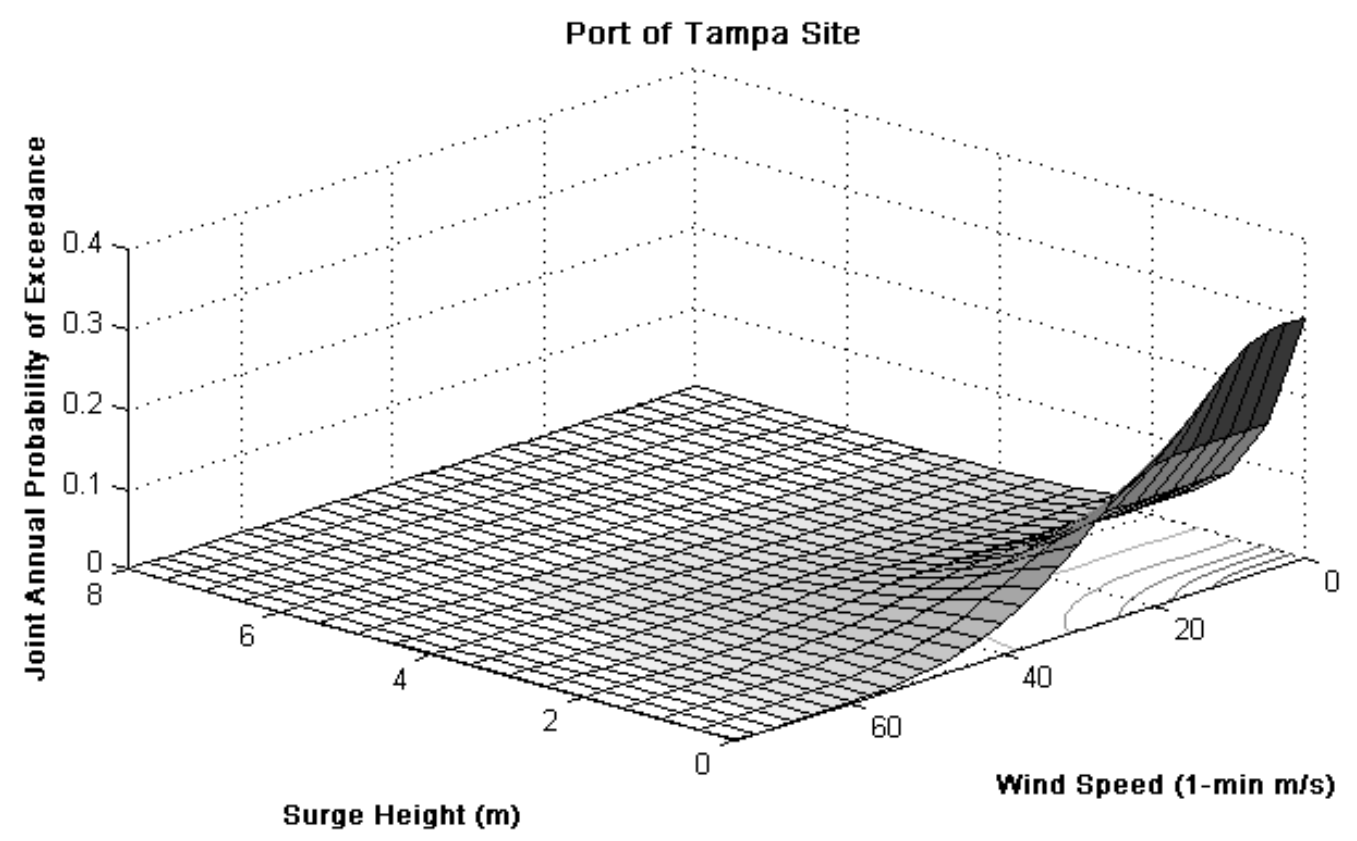

Figure 7(a) Joint Probability of Exceedance for Port of Tampa Site 


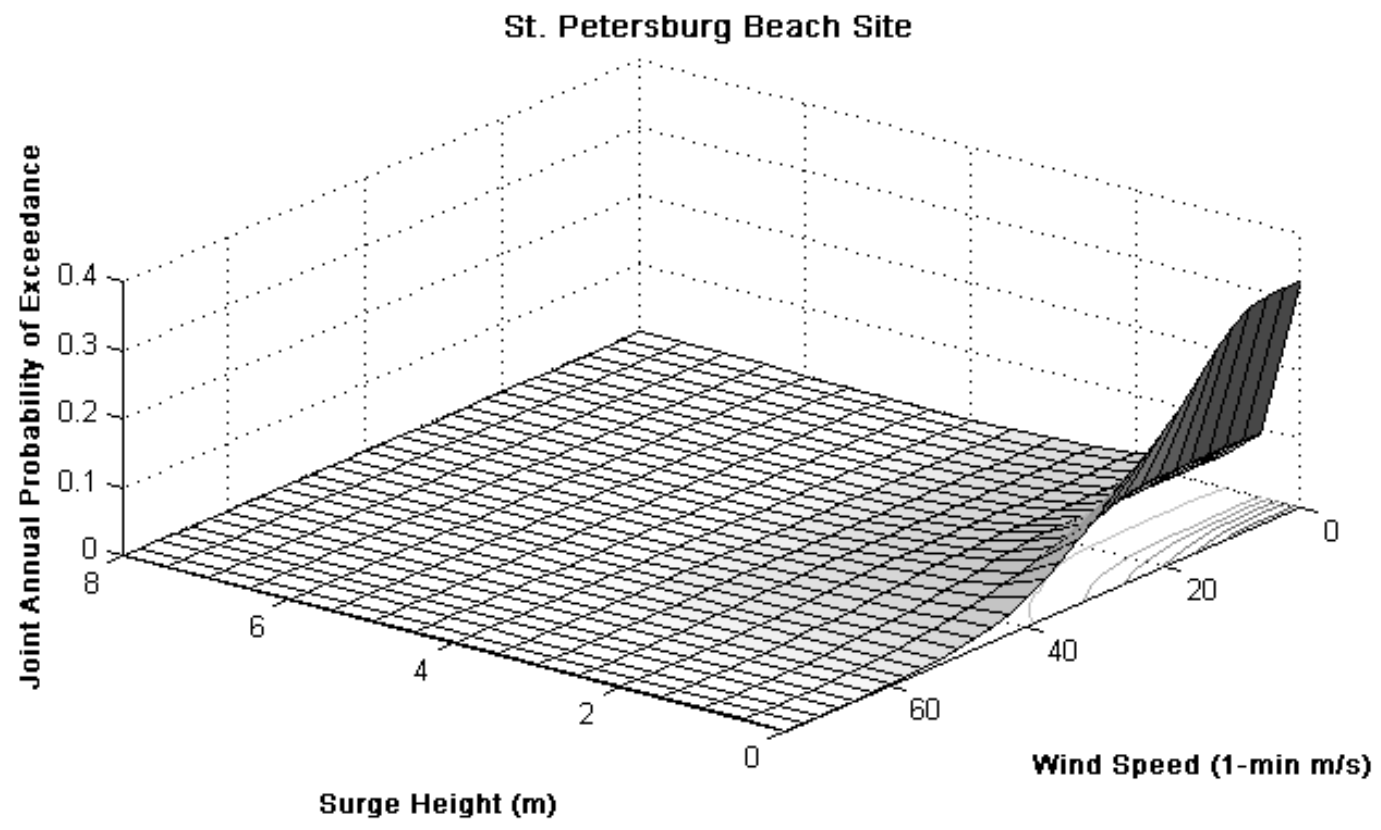

Figure 7(b) Joint Probability of Exceedance for Clearwater Beach Site

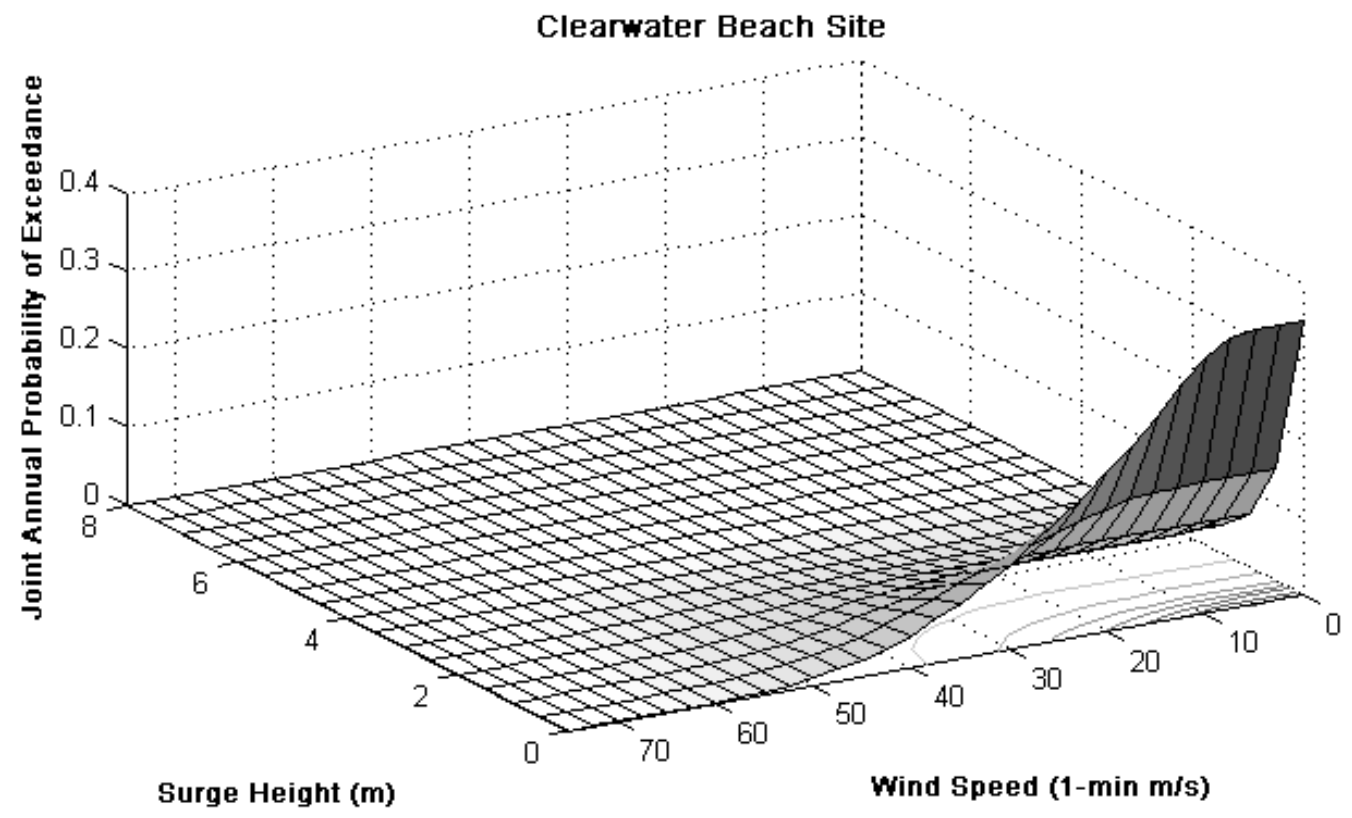




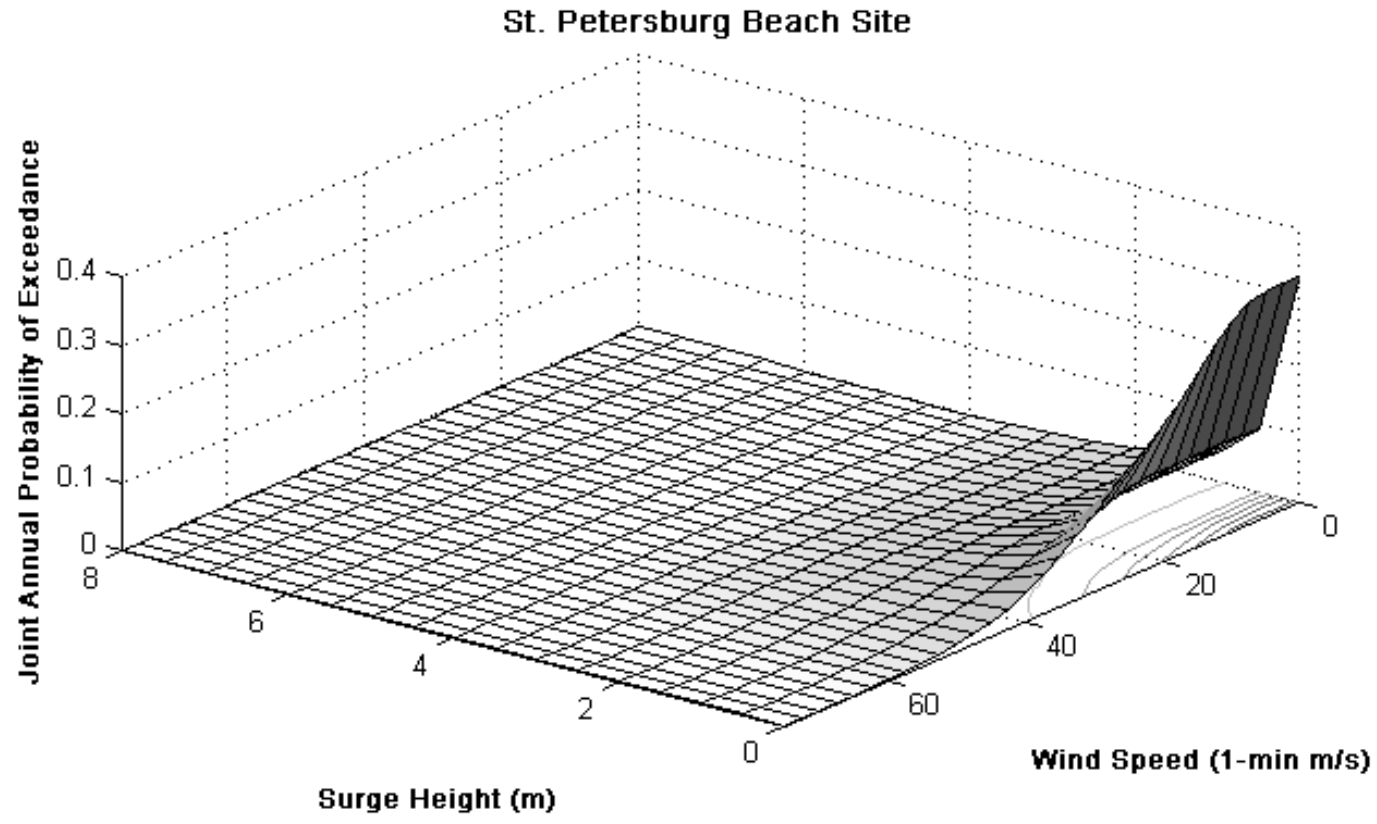

Figure 7(c) Joint Probability of Exceedance for St. Petersburg Beach Site

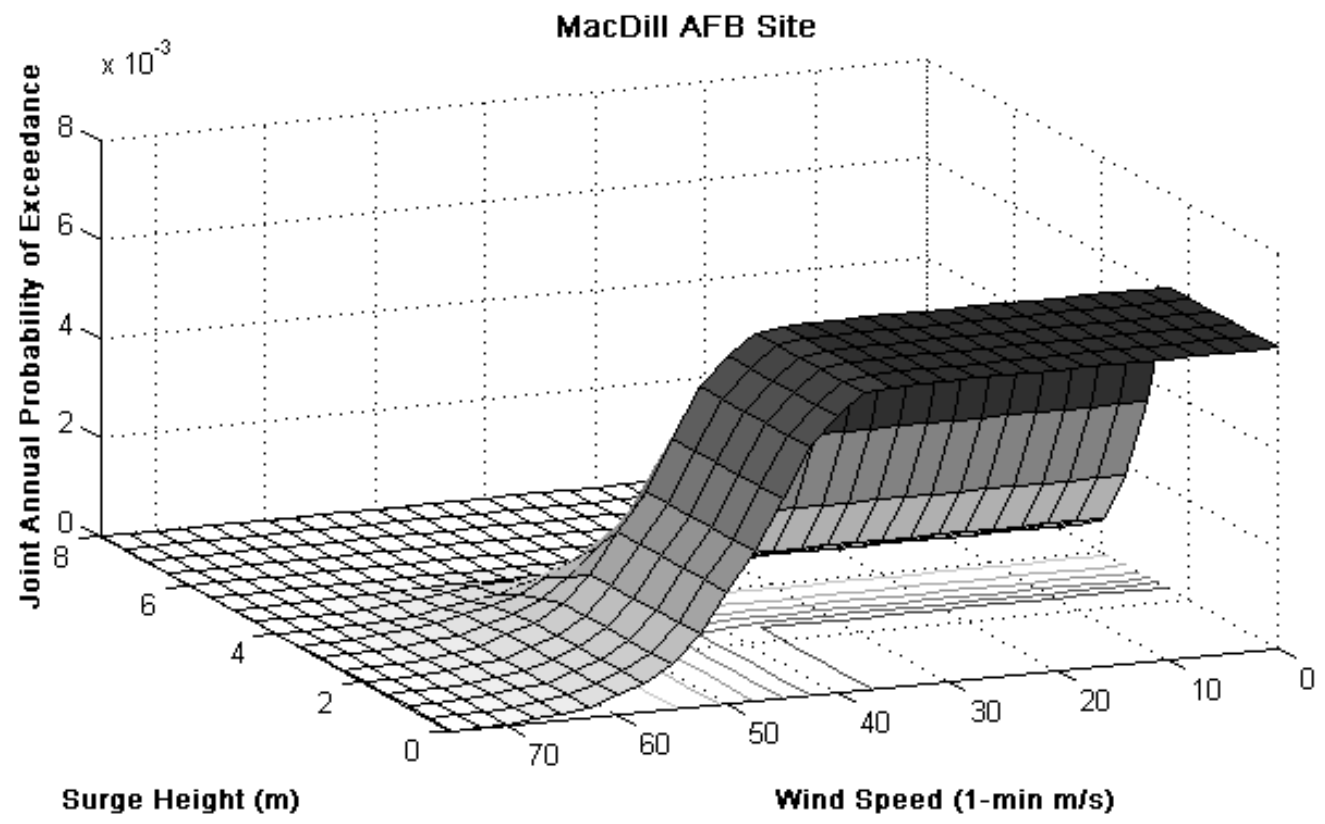

Figure 7(d) Joint Probability of Exceedance for MacDill AFB Site 


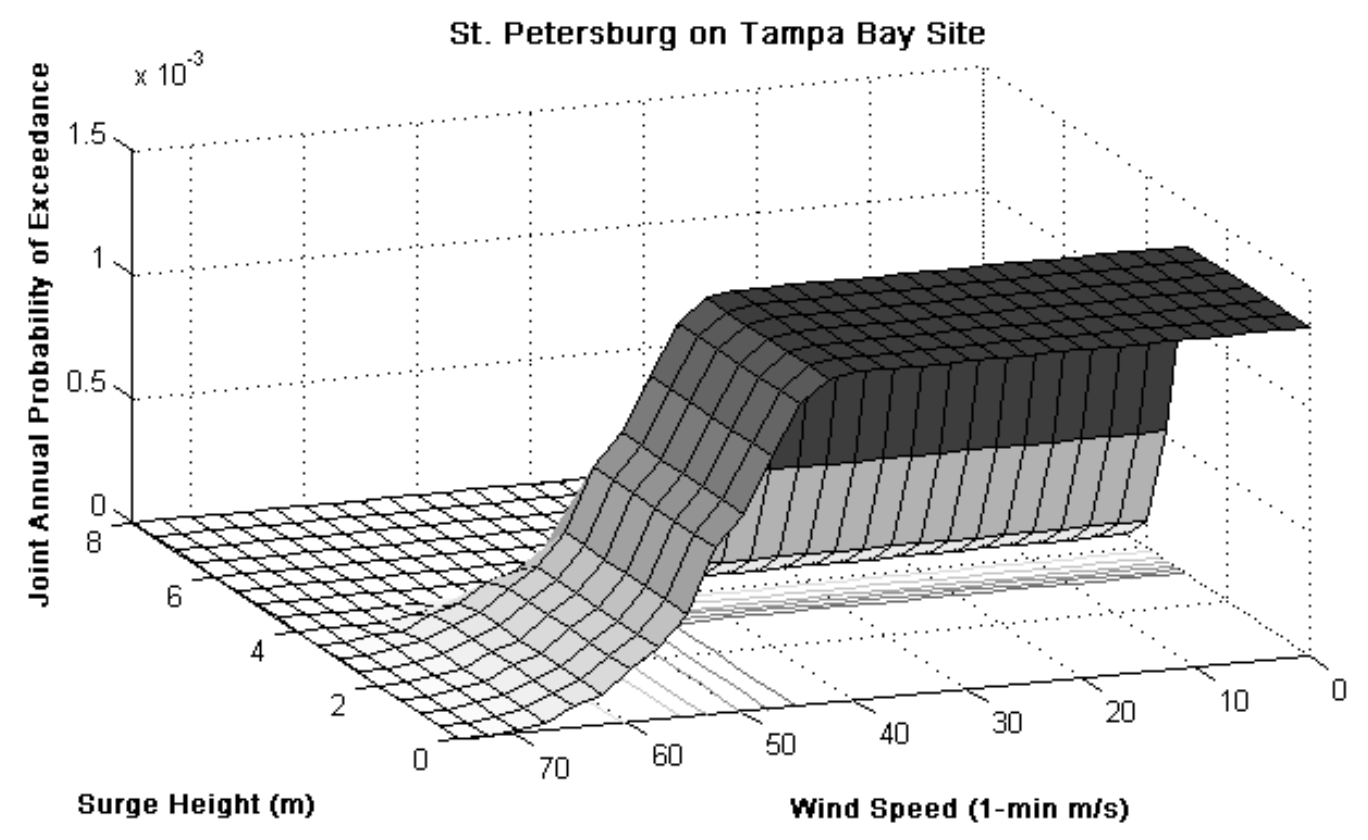

Figure 7(e) Joint Probability of Exceedance for St. Petersburg on Tampa Bay Site

\subsubsection{Marginal Annual Probabilities of Exceedance}

The joint annual probabilities of exceedance computed and shown in Section 3.2.1 can also be used to derived the marginal (or unconditional) annual probabilities of exceedance for each site, i.e., annual probabilities of exceeding various wind speeds regardless of storm surge height and annual probabilities of exceeding various storm surge heights regardless of wind speed. Figures 8(a) and (b) below show the marginal annual probabilities of exceedance of wind speeds and storm surge heights, respectively, for the Port of Tampa site. 


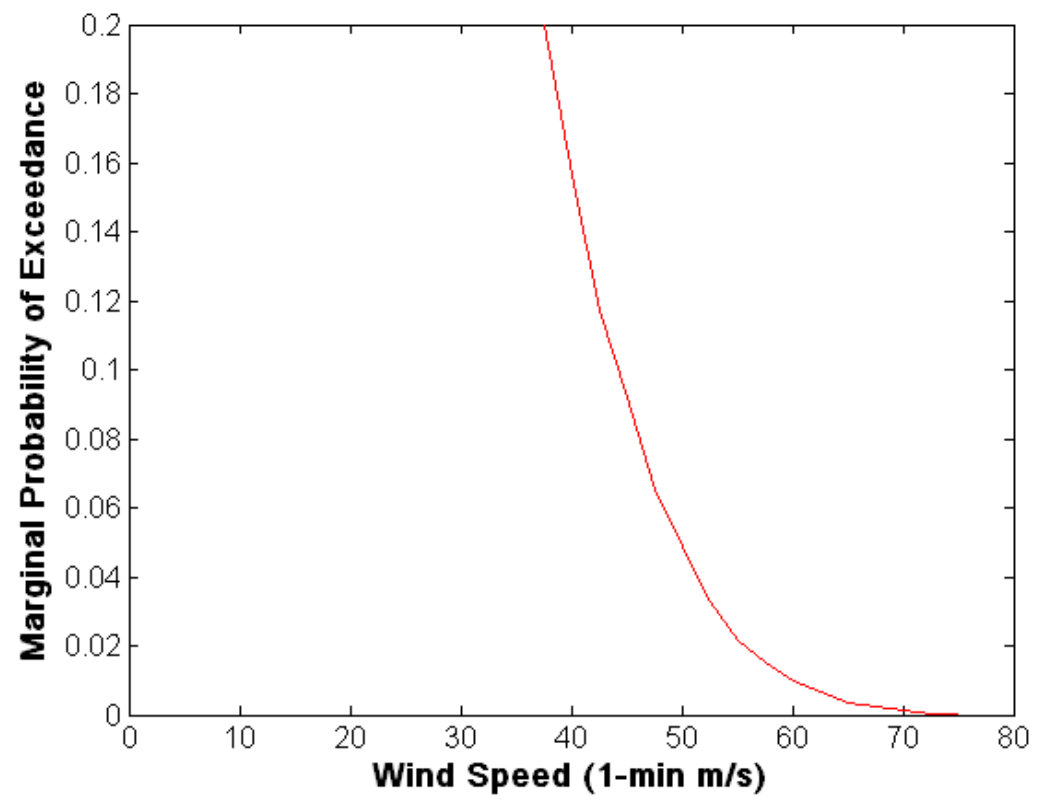

Figure 8(a) Marginal Probability of Exceedance of Wind Speed for Port of Tampa Site

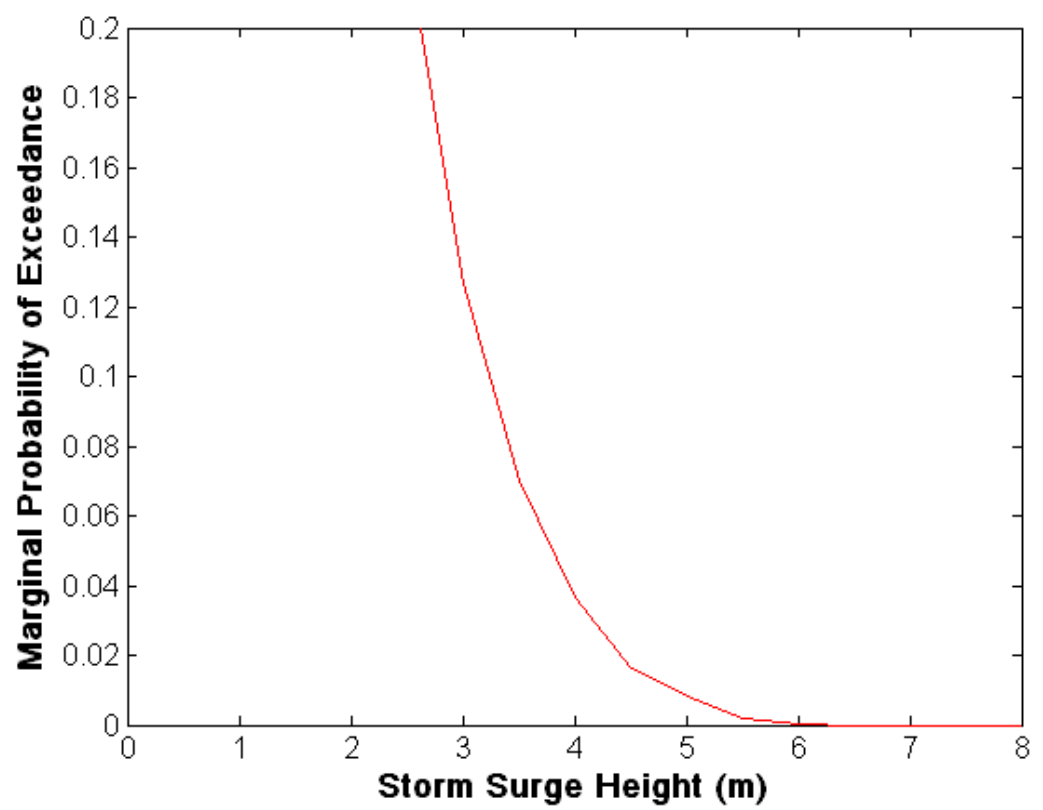

Figure 8(b) Marginal Probability of Exceedance of Storm Surge for Port of Tampa Site 


\subsection{ESTIMATED MEAN RECURRENCE INTERVALS OF JOINT WIND SPEED/STORM SURGE EVENTS}

Finally, we obtain the mean recurrence interval (MRI), in years, of event $v, s$, (i.e., the average time between the occurrence of a wind speed of at least $v$ and a storm surge of at least $s$ ) for each site as the inverse of the bivariate joint annual probability of exceedance of the respective site. MRIs corresponding to various joint wind speed/storm surge height events $(v, s)$ for the five sites are shown in Tables 1 to 5 . It should be noted again that, because the wind speeds and storm surge heights considered in these estimates do not occur simultaneously, the estimates are conservative for design purposes_(see p. 15, footnote 1).

Table 1. MRI (in Years) for Port of Tampa Site

\begin{tabular}{|c|c|c|c|c|c|c|c|c|c|c|}
\hline \multirow{2}{*}{$\begin{array}{c}\text { Wind } \\
\text { Speed } \\
(1-\mathrm{min}) \\
(\mathrm{m} / \mathrm{s})\end{array}$} & \multicolumn{10}{|c|}{ Storm Surge Height (m) } \\
\hline & 1.5 & 2.0 & 2.5 & 3.0 & 3.5 & 4.0 & 4.5 & 5.0 & 5.5 & 6.0 \\
\hline 32.5 & 30 & 49 & 86 & 158 & 299 & 611 & 1447 & 2895 & 13750 & 55000 \\
\hline 35.0 & 35 & 53 & 88 & 158 & 299 & 611 & 1447 & 2895 & 13750 & 55000 \\
\hline 37.5 & 41 & 61 & 92 & 160 & 299 & 611 & 1447 & 2895 & 13750 & 55000 \\
\hline 40.0 & 51 & 76 & 106 & 172 & 302 & 611 & 1447 & 2895 & 13750 & 55000 \\
\hline 42.5 & 66 & 99 & 134 & 190 & 313 & 611 & 1447 & 2895 & 13750 & 55000 \\
\hline 45.0 & 83 & 126 & 165 & 230 & 355 & 625 & 1447 & 2895 & 13750 & 55000 \\
\hline 47.5 & 115 & 174 & 234 & 324 & 451 & 663 & 1447 & 2895 & 13750 & 55000 \\
\hline 50.0 & 149 & 224 & 309 & 414 & 556 & 764 & 1486 & 2895 & 13750 & 55000 \\
\hline 52.5 & 212 & 318 & 455 & 640 & 833 & 1038 & 1618 & 3056 & 13750 & 55000 \\
\hline 55.0 & 320 & 433 & 647 & 982 & 1279 & 1486 & 2115 & 3438 & 13750 & 55000 \\
\hline 57.5 & 447 & 598 & 902 & 1486 & 1964 & 2200 & 2750 & 4583 & 13750 & 55000 \\
\hline 60.0 & 724 & 932 & 1310 & 2292 & 3235 & 3438 & 3929 & 5500 & 13750 & 55000 \\
\hline 62.5 & 1038 & 1375 & 1774 & 3438 & 5500 & 6111 & 6875 & 9167 & 18333 & 55000 \\
\hline 65.0 & 1774 & 2115 & 3056 & 6875 & 13750 & 18333 & 18333 & 27500 & 55000 & \\
\hline 67.5 & 3235 & 3235 & 3929 & 9167 & 27500 & 27500 & 27500 & 55000 & & \\
\hline 70.0 & 5500 & 5500 & 6111 & 13750 & 55000 & 55000 & 55000 & & & \\
\hline
\end{tabular}


Table 2. MRI (in Years) for Clearwater Beach Site

\begin{tabular}{|c|c|c|c|c|c|c|c|c|c|c|}
\hline \multirow{2}{*}{$\begin{array}{c}\text { Wind } \\
\text { Speed } \\
(1-\mathrm{min}) \\
(\mathrm{m} / \mathrm{s})\end{array}$} & \multicolumn{10}{|c|}{ Storm Surge Height (m) } \\
\hline & 1.5 & 2.0 & 2.5 & 3.0 & 3.5 & 4.0 & 4.5 & 5.0 & 5.5 & 6.0 \\
\hline 32.5 & 32 & 52 & 99 & 237 & 797 & 4231 & 18333 & 55000 & & \\
\hline 35.0 & 36 & 55 & 102 & 242 & 809 & 4231 & 18333 & 55000 & & \\
\hline 37.5 & 41 & 61 & 107 & 253 & 821 & 4231 & 18333 & 55000 & & \\
\hline 40.0 & 50 & 72 & 114 & 264 & 859 & 4231 & 18333 & 55000 & & \\
\hline 42.5 & 63 & 90 & 136 & 286 & 887 & 4231 & 18333 & 55000 & & \\
\hline 45.0 & 80 & 113 & 168 & 324 & 932 & 4583 & 18333 & 55000 & & \\
\hline 47.5 & 109 & 149 & 220 & 385 & 1058 & 5000 & 18333 & 55000 & & \\
\hline 50.0 & 152 & 205 & 297 & 462 & 1279 & 6111 & 18333 & 55000 & & \\
\hline 52.5 & 222 & 286 & 404 & 618 & 1667 & 7857 & 27500 & & & \\
\hline 55.0 & 340 & 426 & 604 & 982 & 2500 & 9167 & 27500 & & & \\
\hline 57.5 & 545 & 679 & 948 & 1571 & 3667 & 18333 & 55000 & & & \\
\hline 60.0 & 932 & 1170 & 1528 & 2500 & 6111 & 18333 & 55000 & & & \\
\hline 62.5 & 1774 & 2200 & 2895 & 4583 & 18333 & 55000 & 55000 & & & \\
\hline 65.0 & 2895 & 3056 & 4231 & 7857 & 18333 & 55000 & 55000 & & & \\
\hline 67.5 & 5000 & 5500 & 11000 & 18333 & 27500 & & & & & \\
\hline 70.0 & 11000 & 11000 & 27500 & 27500 & 55000 & & & & & \\
\hline
\end{tabular}

Table 3. MRI (in Years) for St. Petersburg Beach Site

\begin{tabular}{|c|r|r|r|r|r|r|r|r|r|r|}
\hline $\begin{array}{c}\text { Wind } \\
\text { Speed } \\
(\mathbf{1}-\mathbf{m i n})\end{array}$ & \multicolumn{10}{|c|}{ Storm Surge Height (m) } \\
\cline { 2 - 14 }$(\mathbf{m} / \mathbf{s})$ & $\mathbf{1 . 5}$ & $\mathbf{2 . 0}$ & $\mathbf{2 . 5}$ & $\mathbf{3 . 0}$ & $\mathbf{3 . 5}$ & $\mathbf{4 . 0}$ & $\mathbf{4 . 5}$ & $\mathbf{5 . 0}$ & $\mathbf{5 . 5}$ & $\mathbf{6 . 0}$ \\
\hline $\mathbf{3 2 . 5}$ & 45 & 69 & 112 & 253 & 655 & 4583 & & & & \\
\hline $\mathbf{3 5 . 0}$ & 49 & 71 & 114 & 261 & 679 & 4583 & & & & \\
\hline $\mathbf{3 7 . 5}$ & 55 & 75 & 121 & 274 & 714 & 4583 & & & & \\
\hline $\mathbf{4 0 . 0}$ & 66 & 84 & 131 & 299 & 764 & 5500 & & & & \\
\hline $\mathbf{4 2 . 5}$ & 86 & 103 & 153 & 346 & 846 & 5500 & & & & \\
\hline $\mathbf{4 5 . 0}$ & 108 & 127 & 180 & 374 & 887 & 5500 & & & & \\
\hline $\mathbf{4 7 . 5}$ & 142 & 162 & 220 & 423 & 965 & 6875 & & & & \\
\hline $\mathbf{5 0 . 0}$ & 188 & 206 & 275 & 495 & 1019 & 6875 & & & & \\
\hline $\mathbf{5 2 . 5}$ & 282 & 309 & 420 & 663 & 1279 & 7857 & & & & \\
\hline $\mathbf{5 5 . 0}$ & 401 & 451 & 573 & 859 & 1719 & 7857 & & & & \\
\hline $\mathbf{5 7 . 5}$ & 579 & 640 & 786 & 1146 & 2200 & 7857 & & & & \\
\hline $\mathbf{6 0 . 0}$ & 932 & 1038 & 1341 & 1667 & 3235 & 11000 & & & & \\
\hline $\mathbf{6 2 . 5}$ & 1341 & 1447 & 1964 & 2391 & 4583 & 13750 & & & & \\
\hline $\mathbf{6 5 . 0}$ & 2391 & 2500 & 3056 & 3438 & 9167 & 27500 & & & & \\
\hline $\mathbf{6 7 . 5}$ & 3929 & 3929 & 5000 & 5500 & 13750 & 55000 & & & & \\
\hline $\mathbf{7 0 . 0}$ & 9167 & 9167 & 9167 & 11000 & 27500 & 55000 & & & & \\
\hline
\end{tabular}


Table 4. MRI (in Years) for MacDill AFB Site

\begin{tabular}{|c|r|r|r|r|r|r|r|r|r|r|}
\hline $\begin{array}{c}\text { Wind } \\
\text { Speed } \\
(\mathbf{1}-\mathbf{m i n})\end{array}$ & \multicolumn{10}{|c|}{ Storm Surge Height (m) } \\
\cline { 2 - 13 }$(\mathbf{m} / \mathbf{s})$ & $\mathbf{1 . 5}$ & $\mathbf{2 . 0}$ & $\mathbf{2 . 5}$ & $\mathbf{3 . 0}$ & $\mathbf{3 . 5}$ & $\mathbf{4 . 0}$ & $\mathbf{4 . 5}$ & $\mathbf{5 . 0}$ & $\mathbf{5 . 5}$ & $\mathbf{6 . 0}$ \\
\hline $\mathbf{3 2 . 5}$ & 165 & 165 & 165 & 284 & 561 & 1486 & 3235 & 13750 & & \\
\hline $\mathbf{3 5 . 0}$ & 165 & 165 & 165 & 284 & 561 & 1486 & 3235 & 13750 & & \\
\hline $\mathbf{3 7 . 5}$ & 167 & 167 & 167 & 285 & 561 & 1486 & 3235 & 13750 & & \\
\hline $\mathbf{4 0 . 0}$ & 180 & 180 & 180 & 291 & 561 & 1486 & 3235 & 13750 & & \\
\hline $\mathbf{4 2 . 5}$ & 200 & 200 & 200 & 306 & 573 & 1486 & 3235 & 13750 & & \\
\hline $\mathbf{4 5 . 0}$ & 249 & 249 & 249 & 362 & 604 & 1486 & 3235 & 13750 & & \\
\hline $\mathbf{4 7 . 5}$ & 333 & 333 & 333 & 466 & 679 & 1486 & 3235 & 13750 & & \\
\hline $\mathbf{5 0 . 0}$ & 447 & 447 & 447 & 611 & 833 & 1667 & 3235 & 13750 & & \\
\hline $\mathbf{5 2 . 5}$ & 696 & 696 & 696 & 902 & 1122 & 1897 & 3235 & 13750 & & \\
\hline $\mathbf{5 5 . 0}$ & 1122 & 1122 & 1122 & 1341 & 1667 & 2750 & 3929 & 18333 & & \\
\hline $\mathbf{5 7 . 5}$ & 1774 & 1774 & 1774 & 2115 & 2292 & 3929 & 5500 & 18333 & & \\
\hline $\mathbf{6 0 . 0}$ & 2619 & 2619 & 2619 & 3235 & 3438 & 5500 & 6875 & 18333 & & \\
\hline $\mathbf{6 2 . 5}$ & 5500 & 5500 & 5500 & 5500 & 5500 & 11000 & 13750 & 27500 & & \\
\hline $\mathbf{6 5 . 0}$ & 7857 & 7857 & 7857 & 7857 & 7857 & 18333 & 27500 & 55000 & & \\
\hline $\mathbf{6 7 . 5}$ & 18333 & 18333 & 18333 & 18333 & 18333 & & & & & \\
\hline $\mathbf{7 0 . 0}$ & 55000 & 55000 & 55000 & 55000 & 55000 & & & & & \\
\hline
\end{tabular}

Table 5. MRI (in Years) for St. Petersburg on Tampa Bay Site

\begin{tabular}{|c|r|r|r|r|r|r|r|r|r|r|}
\hline $\begin{array}{c}\text { Wind } \\
\text { Speed } \\
\mathbf{( 1 - m i n )}\end{array}$ & \multicolumn{10}{|c|}{ Storm Surge Height (m) } \\
\cline { 2 - 14 }$(\mathbf{m} / \mathbf{s})$ & $\mathbf{1 . 5}$ & $\mathbf{2 . 0}$ & $\mathbf{2 . 5}$ & $\mathbf{3 . 0}$ & $\mathbf{3 . 5}$ & $\mathbf{4 . 0}$ & $\mathbf{4 . 5}$ & $\mathbf{5 . 0}$ & $\mathbf{5 . 5}$ & $\mathbf{6 . 0}$ \\
\hline $\mathbf{3 2 . 5}$ & 753 & 753 & 753 & 753 & 1897 & 9167 & & & & \\
\hline $\mathbf{3 5 . 0}$ & 753 & 753 & 753 & 753 & 1897 & 9167 & & & & \\
\hline $\mathbf{3 7 . 5}$ & 753 & 753 & 753 & 753 & 1897 & 9167 & & & & \\
\hline $\mathbf{4 0 . 0}$ & 753 & 753 & 753 & 753 & 1897 & 9167 & & & & \\
\hline $\mathbf{4 2 . 5}$ & 764 & 764 & 764 & 764 & 1897 & 9167 & & & & \\
\hline $\mathbf{4 5 . 0}$ & 821 & 821 & 821 & 821 & 1897 & 9167 & & & & \\
\hline $\mathbf{4 7 . 5}$ & 982 & 982 & 982 & 982 & 2037 & 9167 & & & & \\
\hline $\mathbf{5 0 . 0}$ & 1250 & 1250 & 1250 & 1250 & 2391 & 9167 & & & & \\
\hline $\mathbf{5 2 . 5}$ & 1486 & 1486 & 1486 & 1486 & 2391 & 9167 & & & & \\
\hline $\mathbf{5 5 . 0}$ & 2391 & 2391 & 2391 & 2391 & 3438 & 11000 & & & & \\
\hline $\mathbf{5 7 . 5}$ & 3438 & 3438 & 3438 & 3438 & 4583 & 13750 & & & & \\
\hline $\mathbf{6 0 . 0}$ & 4583 & 4583 & 4583 & 4583 & 5500 & 13750 & & & & \\
\hline $\mathbf{6 2 . 5}$ & 7857 & 7857 & 7857 & 7857 & 9167 & 27500 & & & & \\
\hline $\mathbf{6 5 . 0}$ & 11000 & 11000 & 11000 & 11000 & 13750 & 55000 & & & & \\
\hline $\mathbf{6 7 . 5}$ & 27500 & 27500 & 27500 & 27500 & 55000 & & & & & \\
\hline $\mathbf{7 0 . 0}$ & 55000 & 55000 & 55000 & 55000 & 55000 & & & & & \\
\hline
\end{tabular}


The interpretation of the results of Table 1 through 5 must take into account the following three observations. First, as indicated in Section 3.1, these variates represent the maximum wind speed occurring at the site during the life of the hurricane with track $h_{i}$, and the maximum storm surge height occurring at the site during the life of that hurricane; these two variates generally do not occur at the same time (see Appendix B). Second, estimates of storm surge height at a site are influenced not only by the maximum wind speed, but also by the hurricane's central barometric pressure, radius of maximum wind_speed, and speed and direction of its forward motion._Thus, hurricanes with_wind speeds of_Category 3 strength, say, can produce extremely high storm surge heights, as has been_the case for hurricane Katrina. Third, probabilities of joint events consisting of wind speed and storm surge height with respect to NGVD at a site depend strongly on the site's geographical position,_bathymetry, and topography.

The first of those observations explains why the MRIs estimated in this report might be smaller than the actual MRIs at a site (i.e., why the MRIs estimated in this report are conservative for structural engineering purposes). The second observation explains why the ordinates of the joint distributions estimated as shown in this report do not necessarily increase monotonically as either of the two variates increases (i.e., the same probabilities of exceedance and MRIs for a range of wind speeds and storm surge heights.) The third observation explains the significant qualitative differences between the joint histograms, probability distributions, and the MRIs estimated for the Port of Tampa, Clearwater Beach, and St. Petersburg sites on the one hand, and the MacDill AFB, and St. Petersburg on Tampa Bay sites on the other. However, a detailed explanation of those differences would require that extensive studies, which_are outside the scope of this report, be performed in the future.

\subsection{ALTERNATIVE METHODS FOR ESTIMATING PROBABILITY OF EXCEEDANCE AND MEAN RECURRENCE INTERVAL}

The above method for calculating joint probability of exceedance and mean recurrence interval utilized $n$ data pairs. Each data pair consisted of the maximum wind speed $v_{i, \max } \equiv \max _{j}\left(v_{i j}\right)$ and maximum storm surge height $s_{i, \max } \equiv \max _{j}\left(s_{i j}\right)$ that occur at different times $j$ in the life of hurricane $i(i=1,2,3 \ldots, n=19,806)$. Denote the sample event space defined by the above data pairs as SE1. As indicated in Sections 3.1 to 3.3, the joint probabilities of exceedance and MRIs developed using event space SE1 are conservative from an engineering design viewpoint.

Other sample event spaces may be considered, for example the sample spaces herein denoted by SE2 and SE3. Event space SE2 is defined by pairs consisting of the maximum wind speed in each hurricane and the largest of the storm surge heights associated with that speed, and pairs consisting of the maximum storm surge height in each hurricane and the largest of the wind speeds associated with that height. Event space SE3 is defined by the set of data pairs that include the total number of $M$ pairs of wind speeds and corresponding storm surge heights that occur during the time period $T$ associated with the $n$ hurricanes $\left(M=m_{1}+m_{2}+\ldots+m_{n}\right.$, and $m_{i}$ is the number of pairs of wind speed/storm surge height data in the $i$ th hurricane, $i=1,2, \ldots, n=19,806$ ). Estimates of joint probabilities of exceedance and mean recurrence intervals for the site of interest using the data pairs defined by event spaces SE2 and SE3 are not carried out in this proof 
of concept phase. However, the estimation procedures and their shortcomings are discussed in Appendix C. 


\section{Chapter 4 \\ Proposed Design CRITERION FOR STRUCTURES SUBJECTED TO COMBINED EFFECT OF WIND AND STORM SURGE}

The steps outlined in Chapters 2 and 3 - which include the simulation and selection of hurricane storm tracks, the hydrodynamic simulation to obtain site-specific wind speeds and corresponding storm surge heights, and the application of probabilistic methods to develop joint probabilities and mean recurrence intervals for wind speed/storm surge height events - constitute a methodology that can be used to develop site-specific, risk-based design criteria for structures subjected to the combined effect of wind speed and storm surge. Two possible approaches for establishing such structural design criteria using the methodology developed in this study are described below.

\subsection{DESIGN CRITERION BASED ON ESTIMATED MRI}

From the MRI table developed as outlined in Chapter 3 for any particular site, the design criterion for structures local to that site can be established as follows:

Ordinary structures shall be designed for the effects of load combinations calculated on the basis of wind speed/storm surge height events with a 50-year MRI if the Allowable Stress Design method is used, or with a 500-year MRI if the Load and Resistance Factor Design method is used.

Special structures shall be designed for load combinations consistent with wind speed/storm surge height events with MRIs determined by the authority having jurisdiction.

The design criterion developed as described in this Section is risk-based and site-specific. The use of data pairs consisting of maximum wind speeds and maximum storm surge heights (defined by event space SE1 in this report) leads to conservative MRI values. The degree of conservatism can be evaluated for specific design situations in a subsequent phase of this study.

\subsection{ALTERNATIVE METHOD FOR ESTABLISHING DESIGN CRITERION}

An alternative approach for establishing the design criterion that is more realistic insofar as it does not entail the same degree of conservatism inherent in the above approach (based on the event space E1) is described in this section. This alternative approach would likely yield less conservative estimates of the requisite exceedance probabilities and mean recurrence intervals, is thus more consistent with the requirements of a performance-based design philosophy, and entails the following steps:

(1) Calculate the combined scalar effect $\sigma_{i j}$ of the wind speed and storm surge for each of the pairs $v_{i j}, s_{i j}$ simulated as shown in Chapter $2(i=1,2, \ldots, n$, where $n=$ number of simulated hurricanes used in the calculations, and $j=1,2, \ldots, m_{i}$, where $m_{i}$ is the number of pairs of data 
points in hurricane $i$ ). The combined effect could, for example, be the maximum stress in a member subjected to gravity loads and to loads induced by both wind load and storm surge. A second example is the aggregate loss of electrical power in a specified region due to damage to overhead power lines induced by wind and damage to underground cables caused by seepage of water following a storm surge and the consequent flooding. A third example is the wind-induced rotation of buildings with floating foundations that would rise in case of flood (the concept of floating foundation has been tried in the Netherlands and is currently being envisaged in the state of Louisiana).

(2) Select, for each hurricane $i$, the largest of the effects $\sigma_{i j}$, denoted by $\sigma_{i}$.

(3) The probabilistic analysis of the univariate time series $\sigma_{i}$ is identical to the analysis applied to hurricane wind speeds, regardless of their direction, or to hurricane wind effects representing the maximum of the directional effects in each of a large number of simulated hurricanes (see Simiu and Miyata, 2006, p. 33). This analysis can yield effects $\sigma_{N}$ corresponding to any mean recurrence intervals $N$ specified by the authority having jurisdiction as a function of type of design and limit state $\sigma_{\text {lim }}$.

(4) A limit state $\sigma_{\lim }$ is specified by the authority having jurisdiction.

(5) For a design to be acceptable the relation $\sigma_{N<} \sigma_{\text {lim }}$ must be satisfied. 


\section{Chapter 5 \\ SUMMARY AND DISCUSSION}

\subsection{SUMMARY}

In this report, we describe a methodology for developing risk-based design criteria for use in designing coastal structures subjected to the combined effects of wind speed and storm surge. The methodology requires, as a first step, the selection of a set of stochastic hurricane storm tracks that affect the area of interest. For this work, we used the existing FPHLM for Florida. The next step involves hydrodynamic simulations of the basin of interest using the program SLOSH, with the selected hurricane tracks as input, to develop time histories of wind speeds and storm surge heights for the sites within the basin. The final step involves the application of probabilistic methods to the time histories of wind speed and storm surge height to produce estimates of joint probabilities of exceedance and mean recurrence intervals of wind speed/storm surge height events, and a corresponding framework for the development of design criteria for the combined effect of wind speed and storm surge that are risk-based and site specific. As proof of concept, the methodology was used to provide conservative estimates of mean recurrence intervals of wind speed/storm surge height events for five locations in the Tampa Bay basin.

In addition to the approach based on estimates of MRIs of joint wind speed/storm surge events at a site, an alternative approach was also proposed for developing design criteria based on response, at every time step, to the combined effect of wind speed and storm surge (e.g., maximum stress in structural members, aggregate loss of power due to wind induced damage to transmission tower or power line, or wind-induced rotation of floating structures). This approach is considered more realistic, i.e., the design criterion developed using this alternative approach is less conservative compared with the joint MRI approach.

\subsection{DISCUSSION}

The methodology outlined in Chapters 2 to 4 of this report provides a state of the art approach to establishing engineering design criteria for the design of coastal structures or other engineering systems, including systems located in the coastal high hazard zones defined by the FEMA's FIRM map and subjected to the combined effect of hurricane wind speed and storm surge. However, the methodology has the following limitations:

- The methodology is applicable only if a stochastic set of hurricane storm tracks and a current hydrodynamic model of the area of interest (SLOSH basins) are available. For the State of Florida, both of these exist, thus design criteria can be developed for the State of Florida using the methodology developed here. Even for Florida the possible evolution in time of the bathymetry of the sites needs to be taken into consideration. Furthermore, changes to the terrain, including both dunes building during beach restoration projects and destruction due 
to hurricane will impact the surge results. For other regions along the eastern seaboard and the Gulf coast, while hydrodynamic models of various basins exist, a public stochastic hurricane simulation model similar to the State of Florida FPHLM may not be available.

- The hydrodynamic simulations performed in this proof of concept study using SLOSH did not consider the effect of waves and tides, both of which would increase the total water levels. Subsequent studies will need to investigate the feasibility of incorporating wave modeling, as well as to consider the effect of tides, in the hydrodynamic simulation and of comparing results with other simulation tools such as the Advanced Circulation Model for Oceanic, Coastal and Estuarine Water (ADCIRC).

- For simplicity, wind directionality was not considered in this proof of concept phase even though time histories of wind direction can be obtained from hydrodynamic simulation by SLOSH. Consideration of wind directionality tends to result in decreased wind effects at a site. This factor needs to be addressed in a subsequent phase of this study. 


\section{Chapter 6 \\ REFERENCES}

ASCE/SEI 7-05, 2005: Minimum Design Loads for Buildings and Other Structures. American Society of Civil Engineers.

ASCE/SEI 24-98, 1998: Flood Resistant Design and Construction. American Society of Civil Engineers.

Darling, R. W. R., 1991: Estimating Probabilities of Hurricane Wind Speeds Using a Large Scale Empirical Model, Journal of Climate, 4, 1035-1046.

DeMaria, M., J. Pennington, and K. Williams, 2002: Description of the Extended Best Track File (EBTRK1.4) version 1.4. Available from NESDIS/CIRA/Regional and Mesoscale Meteorology Team, Colorado State University, Fort Collin, CO.

Ho, F. P., J. C. Su, K. L. Hanevich, R. J. Smith, and F. P. Richards, 1987: Hurricane climatology for the Atlantic and Gulf coasts of the United States. NOAA Tech Memo NWS 38, NWS Silver Spring, MD.

Holland, G. J., 1980: An analytic model of the wind and pressure profiles in hurricanes, Mon. Wea. Rev., 108, 1212-1218.

Houston, S. H., and M. D. Powell, 1994: Observed and modeled wind and water level response from Tropical Storm Marco (1990). Wea. Forecast., 9,427-439.

Houston, S. H., W. A. Shaffer, M. D. Powell, and J. Chen, 1999: Comparisons of HRD and SLOSH surface wind fields in hurricanes: Implications for storm surge and wave modeling. Wea. Forecast., 14, 671-686.

Jelesnianski, C.P., J. Chen, W.A. Shaffer, 1992: SLOSH Sea, Lake, and Overland Surges from Hurricanes, NOAA Technical Report NWS 48, Silverspring, Maryland.

NIST Technical Note 1476, Performance of Physical Structures in Hurricane Katrina and Hurricane Rita: A Reconnaissance Report, National Institute of Standards and Technology, 2006.

Pennington, J., M. DeMaria, and K. Williams, cited 2000: Development of a 10-year Atlantic basin tropical cyclone wind structure climatology.

(Available online at www.bbsr.edu/rpi/research/demaria/demaria4.html) 
Powell, M. D., G. Soukup, S. Cocke, S. Gulati, N. Morisseau-Leroy, S. Hamid, N. Dorst, and L. Axe, 2005: State of Florida hurricane loss projection model: Atmospheric science component. $J$. Wind Engineer. and Indust. Aerodyn., 93, 651-674.

Saffir, H.S., 1989: Florida's Approach to Hurricane-Resistant Design and Construction, Journal of Wind Engineering and Industrial Aerodynamics, Elsevier Science Publishers B.V., Amsterdam, The Netherlands, pp. 221-230.

Simiu, E., and T. Miyata, 2006: Design of Buildings and Bridges for Wind: A Practical Guide for ASCE-7 Standard Users and Designers of Special Structures, John Wiley and Sons, Inc.

Vickery, P. J., and L.A. Twisdale, 2005: Wind Field and Filling Models for Hurricane Wind Speed Predictions, Journal of Structural Engineering, 121, 1700-1709.

Willoughby, H. E., and M. E. Rahn, 2004: Parametric Representation of the Primary Hurricane Vortex. Part I: Observations and Evaluation of the Holland (1980) Model. Mon. Wea. Rev., 132, 3033-3048.

http://www.nhc.noaa.gov/aboutsshs.shtml 


\section{Appendix A \\ EXPLANATION OF SLOSH SIMULATION OUTPUT}

Wind Directions, Wind Speeds, and Storm Surge Heights at Clear Water Beach Location $(27.9767 \mathrm{~N}, 82.8366 \mathrm{~W})$ caused by hurricane storm track number 12364 (generated from 55,000year simulation for State of Florida FPHLM, Version 1.0)

\begin{tabular}{|c|c|c|c|c|c|}
\hline \\
\hline \multicolumn{6}{|c|}{$\begin{array}{l}\text { RexFile=SLOSHRexFiles/adjSLOSHtrk12364.rex } \\
(48 \text { 26) }(27.9767-82.8366) \\
\text { time (min), } \mathrm{i}, \mathrm{j}, \text { lat, lon, wind } \operatorname{dir}(0 \text { is wind going eastward), wind speed ( } 1 \text { min } \mathrm{MPH}) \text {, surge }(\mathrm{ft}) \\
\begin{array}{ll}0.00,48, \\
26,\end{array}\end{array}$} \\
\hline $4.50, \quad 48$ & 26 & $27.9767,-82.8366$ & 131 , & 29 , & 2.1 \\
\hline $9.50, \quad 48$ & 26 & $27.9767,-82.8366$ & 131 , & 29 & 2.2 \\
\hline $14.50,48$ & 26 & $27.9767,-82.8366$ & 131, & 29 & 2.2 \\
\hline $19.50,48$ & 26 & $27.9767,-82.8366$ & 130 , & 29 & 2.2 \\
\hline $24.50,48$ & 26 & $27.9767,-82.8366$ & 130 , & 29 & 2.2 \\
\hline $29.50,48$, & 26 , & 27.9767, -82.8366, & 130 , & 29 , & 2.2 \\
\hline $34.50,48$, & 26 & $27.9767,-82.8366$, & 129 , & 29 , & 2.2 \\
\hline $39.50,48$ & 26 & $27.9767,-82.8366$ & 129 , & 29 & 2.2 \\
\hline $44.50,48$ & 26 & $27.9767,-82.8366$ & 129 , & 29 & 2.2 \\
\hline $49.50,48$ & 26 & $27.9767,-82.8366$, & 128 , & 29 , & 2.1 \\
\hline $54.50,48$ & 26 & $27.9767,-82.8366$, & 128 , & 28 & 2.1 \\
\hline $674.50,48$ & 26 & $27.9767,-82.8366$, & 80 & 18 , & 2.9 \\
\hline $679.50,48$ & 26 , & $27.9767,-82.8366$, & 80 & 18 & 2.9 \\
\hline $684.50,48$ & 26 & 27.9767, -82.8366, & 80 & 18 & 2.9 \\
\hline $689.50,48$ & 26 & $27.9767,-82.8366$ & 79 & 18 & 2.9 \\
\hline $694.50,48$ & 26 & $27.9767,-82.8366$ & 79 & 18 & 2.9 \\
\hline $699.50,48$ & 26 , & $27.9767,-82.8366$, & 79 & 17 & 2.9 \\
\hline $704.50,48$ & 26 & $27.9767,-82.8366$, & 79 & 17 , & 2.9 \\
\hline $709.50,48$ & 26 & $27.9767,-82.8366$ & 78 & 17 & 2.8 \\
\hline $714.50,48$ & 26 , & $27.9767,-82.8366$, & 78 & 17 , & 2.8 \\
\hline $719.50,48$ & 26 & $27.9767,-82.8366$ & 78 & 17 & 2.8 \\
\hline
\end{tabular}

Explanation of SLOSH Output:

- Row 1: Identification of hurricane track for the FPHLM used in the simulation

- Row 2: SLOSH grid locator $(\mathrm{i} / \mathrm{j})$ and associated lat/lon of the site of interest

- Row 3: Keys defining subsequent data columns:
o Column 1: $\quad$ Time step in minutes
o Column 2: $\quad$ SLOSH I, of $\mathrm{i} / \mathrm{j}$ grid locator
o Column 3: $\quad$ SLOSH $\mathrm{J}$, of $\mathrm{i} / \mathrm{j}$ grid locator
o Column 4: Latitude of the site of interest
o Column 5: Longitude of the site of interest
o Column 6: Wind direction ( 0 is wind blowing eastward)
o Column 7: Wind speed (1-min $\mathrm{MPH}$ )
o Column 8: Storm surge height (ft) 


\section{Appendix B}

\section{Typical Slosh Simulation OUTPUT for The Port of TAMPa Site}

RexFile=DataSets/SLOSHRexFiles/etpa SLOSHtrk 160.rex

\section{(18 10) (27.9475 -82.4448)}

time (min), i, j, lat, lon, wind dir (0 is wind going eastward), wind speed (1 min MPH), surge (ft)

$0.00,18,10,27.9475,-82.4448,-116,12,0.0$ $4.50,18,10,27.9475,-82.4448,-116,13,0.0$ $9.50,18,10,27.9475,-82.4448,-116,13,0.0$ $14.50,18,10,27.9475,-82.4448,-117,13,0.0$ $19.50,18,10,27.9475,-82.4448,-117,13,0.0$ $24.50,18,10,27.9475,-82.4448,-117,13,0.0$ $29.50,18,10,27.9475,-82.4448,-117,13,0.0$ $34.50,18,10,27.9475,-82.4448,-117,13,0.0$ $39.50,18,10,27.9475,-82.4448,-117,13,0.0$ $44.50,18,10,27.9475,-82.4448,-117,13,0.0$ $49.50,18,10,27.9475,-82.4448,-117,13,0.0$ $54.50,18,10,27.9475,-82.4448,-117,13,0.0$ $59.50,18,10,27.9475,-82.4448,-117,13,0.0$ $64.50,18,10,27.9475,-82.4448,-117,13,0.0$ $69.50,18,10,27.9475,-82.4448,-117,13,0.0$ $74.50,18,10,27.9475,-82.4448,-117,13,0.0$ $79.50,18,10,27.9475,-82.4448,-117,13,0.0$ $84.50,18,10,27.9475,-82.4448,-117,13,0.0$ $89.50,18,10,27.9475,-82.4448,-117,13,0.0$ $94.50,18,10,27.9475,-82.4448,-117,14,0.0$ $99.50,18,10,27.9475,-82.4448,-117,14,0.0$ $104.50,18,10,27.9475,-82.4448,-117,14,0.0$ $109.50,18,10,27.9475,-82.4448,-117,14,0.0$ $114.50,18,10,27.9475,-82.4448,-117,14,0.0$ $119.50,18,10,27.9475,-82.4448,-117,14,0.0$ $124.50,18,10,27.9475,-82.4448,-117,14,0.0$ $129.50,18,10,27.9475,-82.4448,-117,14,0.0$ $134.50,18,10,27.9475,-82.4448,-117,14,0.0$ $139.50,18,10,27.9475,-82.4448,-117,14,0.0$ $144.50,18,10,27.9475,-82.4448,-117,14,0.0$ $149.50,18,10,27.9475,-82.4448,-117,14,0.0$
$154.50,18,10,27.9475,-82.4448,-117,14,0.0$ $159.50,18,10,27.9475,-82.4448,-118,14,0.0$ $164.50,18,10,27.9475,-82.4448,-118,14,0.0$ $169.50,18,10,27.9475,-82.4448,-118,15,0.0$ $174.50,18,10,27.9475,-82.4448,-118,15,0.0$ $179.50,18,10,27.9475,-82.4448,-118,15,0.0$ $184.50,18,10,27.9475,-82.4448,-118,15,0.0$ $189.50,18,10,27.9475,-82.4448,-118,15,0.0$ $194.50,18,10,27.9475,-82.4448,-118,15,0.0$ $199.50,18,10,27.9475,-82.4448,-118,15,0.0$ $204.50,18,10,27.9475,-82.4448,-118,15,0.0$ $209.50,18,10,27.9475,-82.4448,-118,15,0.0$ $214.50,18,10,27.9475,-82.4448,-118,15,0.0$ $219.50,18,10,27.9475,-82.4448,-118,15,0.0$ $224.50,18,10,27.9475,-82.4448,-118,15,0.0$ $229.50,18,10,27.9475,-82.4448,-118,15,0.0$ $234.50,18,10,27.9475,-82.4448,-118,15,0.0$ $239.50,18,10,27.9475,-82.4448,-118,16,0.0$ $244.50,18,10,27.9475,-82.4448,-118,16,-0.1$ $249.50,18,10,27.9475,-82.4448,-118,16,-0.1$ $254.50,18,10,27.9475,-82.4448,-118,16,-0.1$ $259.50,18,10,27.9475,-82.4448,-118,16,-0.1$ $264.50,18,10,27.9475,-82.4448,-118,16,-0.1$ $269.50,18,10,27.9475,-82.4448,-118,16,-0.1$ $274.50,18,10,27.9475,-82.4448,-118,16,-0.1$ $279.50,18,10,27.9475,-82.4448,-118,16,-0.1$ $284.50,18,10,27.9475,-82.4448,-118,16,-0.1$ $289.50,18,10,27.9475,-82.4448,-118,16,-0.1$ $294.50,18,10,27.9475,-82.4448,-118,16,-0$. $299.50,18,10,27.9475,-82.4448,-118,16,-0.1$ $304.50,18,10,27.9475,-82.4448,-118,16,-0.1$ $309.50,18,10,27.9475,-82.4448,-119,17,-0.1$ $314.50,18,10,27.9475,-82.4448,-119,17,-0.1$ $319.50,18,10,27.9475,-82.4448,-119,17,-0.1$ $324.50,18,10,27.9475,-82.4448,-119,17,-0.1$ $329.50,18,10,27.9475,-82.4448,-119,17,-0$. $334.50,18,10,27.9475,-82.4448,-119,17,-0.1$ $339.50,18,10,27.9475,-82.4448,-119,17,-0.1$
$344.50,18,10,27.9475,-82.4448,-119,17,-0.1$ $349.50,18,10,27.9475,-82.4448,-119,17,-0.1$ $354.50,18,10,27.9475,-82.4448,-119,17,-0.1$ $359.50,18,10,27.9475,-82.4448,-119,17,-0.1$ $364.50,18,10,27.9475,-82.4448,-119,18,-0.1$ $369.50,18,10,27.9475,-82.4448,-119,18,-0.1$ $374.50,18,10,27.9475,-82.4448,-119,18,-0.1$ $379.50,18,10,27.9475,-82.4448,-119,18,-0.2$ $384.50,18,10,27.9475,-82.4448,-119,18,-0.2$ $389.50,18,10,27.9475,-82.4448,-120,18,-0.2$ $394.50,18,10,27.9475,-82.4448,-120,18,-0.2$ $399.50,18,10,27.9475,-82.4448,-120,18,-0.2$ $404.50,18,10,27.9475,-82.4448,-120,18,-0.2$ $409.50,18,10,27.9475,-82.4448,-120,18,-0.2$ $414.50,18,10,27.9475,-82.4448,-120,18,-0.2$ $419.50,18,10,27.9475,-82.4448,-120,18,-0.2$ $424.50,18,10,27.9475,-82.4448,-120,18,-0.2$ $429.50,18,10,27.9475,-82.4448,-120,18,-0.2$ $434.50,18,10,27.9475,-82.4448,-121,18,-0.2$ $439.50,18,10,27.9475,-82.4448,-121,18,-0.2$ $444.50,18,10,27.9475,-82.4448,-121,18,-0.2$ $449.50,18,10,27.9475,-82.4448,-121,18,-0.2$ $454.50,18,10,27.9475,-82.4448,-121,19,-0.2$ $459.50,18,10,27.9475,-82.4448,-121,19,-0.2$ $464.50,18,10,27.9475,-82.4448,-121,19,-0.2$ $469.50,18,10,27.9475,-82.4448,-121,19,-0.3$ $474.50,18,10,27.9475,-82.4448,-122,19,-0.3$ $479.50,18,10,27.9475,-82.4448,-122,19,-0.3$ $484.50,18,10,27.9475,-82.4448,-122,19,-0.3$ $489.50,18,10,27.9475,-82.4448,-122,19,-0.3$ $494.50,18,10,27.9475,-82.4448,-122,19,-0.3$ $499.50,18,10,27.9475,-82.4448,-122,19,-0.3$ $504.50,18,10,27.9475,-82.4448,-122,19,-0.3$ $509.50,18,10,27.9475,-82.4448,-122,20,-0.3$ $514.50,18,10,27.9475,-82.4448,-122,20,-0.3$ $519.50,18,10,27.9475,-82.4448,-123,20,-0.3$ $524.50,18,10,27.9475,-82.4448,-123,20,-0.3$ $529.50,18,10,27.9475,-82.4448,-123,20,-0.3$ 
$534.50,18,10,27.9475,-82.4448,-123,20,-0.3$ $539.50,18,10,27.9475,-82.4448,-123,20,-0.3$ $544.50,18,10,27.9475,-82.4448,-123,20,-0.3$ $549.50,18,10,27.9475,-82.4448,-123,20,-0.3$ $554.50,18,10,27.9475,-82.4448,-123,21,-0.3$ $559.50,18,10,27.9475,-82.4448,-123,21,-0.3$ $564.50,18,10,27.9475,-82.4448,-123,21,-0.4$ $569.50,18,10,27.9475,-82.4448,-123,21,-0.4$ $574.50,18,10,27.9475,-82.4448,-123,21,-0.4$ $579.50,18,10,27.9475,-82.4448,-123,21,-0.4$ $584.50,18,10,27.9475,-82.4448,-123,21,-0.4$ $589.50,18,10,27.9475,-82.4448,-124,21,-0.4$ $594.50,18,10,27.9475,-82.4448,-124,21,-0.4$ $599.50,18,10,27.9475,-82.4448,-124,22,-0.4$ $604.50,18,10,27.9475,-82.4448,-124,22,-0.4$ $609.50,18,10,27.9475,-82.4448,-124,22,-0.4$ $614.50,18,10,27.9475,-82.4448,-124,22,-0.4$ $619.50,18,10,27.9475,-82.4448,-124,22,-0.4$ $624.50,18,10,27.9475,-82.4448,-124,22,-0.4$ $629.50,18,10,27.9475,-82.4448,-124,22,-0.4$ $634.50,18,10,27.9475,-82.4448,-124,22,-0.4$ $639.50,18,10,27.9475,-82.4448,-125,23,-0.4$ $644.50,18,10,27.9475,-82.4448,-125,23,-0.4$ $649.50,18,10,27.9475,-82.4448,-125,23,-0.5$ $654.50,18,10,27.9475,-82.4448,-125,23,-0.5$ $659.50,18,10,27.9475,-82.4448,-125,23,-0.5$ $664.50,18,10,27.9475,-82.4448,-125,23,-0.5$ $669.50,18,10,27.9475,-82.4448,-125,23,-0.5$ $674.50,18,10,27.9475,-82.4448,-125,23,-0.5$ $679.50,18,10,27.9475,-82.4448,-126,24,-0.5$ $684.50,18,10,27.9475,-82.4448,-126,24,-0.5$ $689.50,18,10,27.9475,-82.4448,-126,24,-0.5$ $694.50,18,10,27.9475,-82.4448,-126,24,-0.5$ $699.50,18,10,27.9475,-82.4448,-126,24,-0.5$ $704.50,18,10,27.9475,-82.4448,-126,24,-0.5$ $709.50,18,10,27.9475,-82.4448,-126,24,-0.6$ $714.50,18,10,27.9475,-82.4448,-126,25,-0.6$ $719.50,18,10,27.9475,-82.4448,-126,24,-0.6$ $724.50,18,10,27.9475,-82.4448,-126,24,-0.6$ $729.50,18,10,27.9475,-82.4448,-126,25,-0.6$ $734.50,18,10,27.9475,-82.4448,-126,25,-0.6$ $739.50,18,10,27.9475,-82.4448,-126,25,-0.6$ $744.50,18,10,27.9475,-82.4448,-126,25,-0.6$ $749.50,18,10,27.9475,-82.4448,-126,25,-0.6$ $754.50,18,10,27.9475,-82.4448,-126,26,-0.6$
$759.50,18,10,27.9475,-82.4448,-126,26,-0.6$ $764.50,18,10,27.9475,-82.4448,-126,26,-0.7$ $769.50,18,10,27.9475,-82.4448,-126,26,-0.7$ $774.50,18,10,27.9475,-82.4448,-126,27,-0.7$ $779.50,18,10,27.9475,-82.4448,-125,27,-0.7$ $784.50,18,10,27.9475,-82.4448,-125,27,-0.7$ $789.50,18,10,27.9475,-82.4448,-125,27,-0.7$ $794.50,18,10,27.9475,-82.4448,-125,28,-0.7$ $799.50,18,10,27.9475,-82.4448,-125,28,-0.7$ $804.50,18,10,27.9475,-82.4448,-126,28,-0.8$ $809.50,18,10,27.9475,-82.4448,-126,28,-0.8$ $814.50,18,10,27.9475,-82.4448,-126,29,-0.8$ $819.50,18,10,27.9475,-82.4448,-126,29,-0.8$ $824.50,18,10,27.9475,-82.4448,-126,29,-0.8$ $829.50,18,10,27.9475,-82.4448,-126,30,-0.8$ $834.50,18,10,27.9475,-82.4448,-126,30,-0.8$ $839.50,18,10,27.9475,-82.4448,-126,30,-0.9$ $844.50,18,10,27.9475,-82.4448,-126,31,-0.9$ $849.50,18,10,27.9475,-82.4448,-126,31,-0.9$ $854.50,18,10,27.9475,-82.4448,-126,32,-0.9$ $859.50,18,10,27.9475,-82.4448,-126,32,-0.9$ $864.50,18,10,27.9475,-82.4448,-126,32,-0.9$ $869.50,18,10,27.9475,-82.4448,-126,33,-1.0$ $874.50,18,10,27.9475,-82.4448,-126,33,-1.0$ $879.50,18,10,27.9475,-82.4448,-126,33,-1.0$ $884.50,18,10,27.9475,-82.4448,-126,34,-1.0$ $889.50,18,10,27.9475,-82.4448,-126,34,-1.0$ $894.50,18,10,27.9475,-82.4448,-126,35,-1.1$ $899.50,18,10,27.9475,-82.4448,-127,35,-1.1$ $904.50,18,10,27.9475,-82.4448,-127,36,-1.1$ $909.50,18,10,27.9475,-82.4448,-127,36,-1.1$ $914.50,18,10,27.9475,-82.4448,-127,36,-1.1$ $919.50,18,10,27.9475,-82.4448,-127,37,-1.2$ $924.50,18,10,27.9475,-82.4448,-127,37,-1.2$ $929.50,18,10,27.9475,-82.4448,-127,38,-1.2$ $934.50,18,10,27.9475,-82.4448,-127,38,-1.2$ $939.50,18,10,27.9475,-82.4448,-128,39,-1.3$ $944.50,18,10,27.9475,-82.4448,-128,39,-1.3$ $949.50,18,10,27.9475,-82.4448,-128,40,-1.3$ $954.50,18,10,27.9475,-82.4448,-128,41,-1.3$ $959.50,18,10,27.9475,-82.4448,-128,41,-1.3$ $964.50,18,10,27.9475,-82.4448,-129,42,-1.4$ $969.50,18,10,27.9475,-82.4448,-129,43,-1.4$ $974.50,18,10,27.9475,-82.4448,-129,43,-1.4$ $979.50,18,10,27.9475,-82.4448,-129,44,-1.5$
$984.50,18,10,27.9475,-82.4448,-130,44,-1.5$ $989.50,18,10,27.9475,-82.4448,-130,45,-1.5$ $994.50,18,10,27.9475,-82.4448,-130,46,-1.5$ $999.50,18,10,27.9475,-82.4448,-131,46,-1.6$ $004.50,18,10,27.9475,-82.4448,-131,47,-1.6$ $1009.50,18,10,27.9475,-82.4448,-131,48,-1.6$ $1014.50,18,10,27.9475,-82.4448,-132,49,-1.6$ $1019.50,18,10,27.9475,-82.4448,-132,49,-1.7$ $1024.50,18,10,27.9475,-82.4448,-132,50,-1.7$ $1029.50,18,10,27.9475,-82.4448,-133,51,-1.7$ $1034.50,18,10,27.9475,-82.4448,-133,52,-1.8$ $039.50,18,10,27.9475,-82.4448,-134,53,-1.8$ $1044.50,18,10,27.9475,-82.4448,-135,54,-1.8$ $1049.50,18,10,27.9475,-82.4448,-135,55,-1.8$ $1054.50,18,10,27.9475,-82.4448,-136,56,-1.8$ $1059.50,18,10,27.9475,-82.4448,-137,57,-1.8$ $1064.50,18,10,27.9475,-82.4448,-138,58,-1.8$ $1069.50,18,10,27.9475,-82.4448,-139,59,-1.9$ $1074.50,18,10,27.9475,-82.4448,-140,60,-1.9$ $1079.50,18,10,27.9475,-82.4448,-143,60,-1.9$ $1084.50,18,10,27.9475,-82.4448,-144,61,-1.9$ $1089.50,18,10,27.9475,-82.4448,-144,62,-1.9$ $1094.50,18,10,27.9475,-82.4448,-145,62,-1.9$ $1099.50,18,10,27.9475,-82.4448,-146,63,-1.9$ $1104.50,18,10,27.9475,-82.4448,-146,64,-1.9$ $1109.50,18,10,27.9475,-82.4448,-147,65,-1.9$ $1114.50,18,10,27.9475,-82.4448,-148,66,-1.9$ $1119.50,18,10,27.9475,-82.4448,-149,67,-1.9$ $1124.50,18,10,27.9475,-82.4448,-150,68,-1.9$ $1129.50,18,10,27.9475,-82.4448,-151,69,-1.9$ $1134.50,18,10,27.9475,-82.4448,-152,70,-1.9$ $1139.50,18,10,27.9475,-82.4448,-153,71,-1.9$ $1144.50,18,10,27.9475,-82.4448,-155,71,-1.9$ $1149.50,18,10,27.9475,-82.4448,-156,72,-1.9$ $1154.50,18,10,27.9475,-82.4448,-158,73,-1.9$ $1159.50,18,10,27.9475,-82.4448,-159,74,-1.9$ $1164.50,18,10,27.9475,-82.4448,-161,75,99.9$ $1169.50,18,10,27.9475,-82.4448,-163,76,99.9$ $1174.50,18,10,27.9475,-82.4448,-165,77,99.9$ $1179.50,18,10,27.9475,-82.4448,-167,77,99.9$ $1184.50,18,10,27.9475,-82.4448,-169,78,99.9$ $1189.50,18,10,27.9475,-82.4448,-171,79,99.9$ $1194.50,18,10,27.9475,-82.4448,-174,79,99.9$ $1199.50,18,10,27.9475,-82.4448,-176,80,99.9$ $1204.50,18,10,27.9475,-82.4448,-178,80,99.9$ 
$1209.50,18,10,27.9475,-82.4448,179,81,99.9$ $1214.50,18,10,27.9475,-82.4448,177,81,99.9$ $1219.50,18,10,27.9475,-82.4448,174,82,99.9$ $1224.50,18,10,27.9475,-82.4448,171,82,99.9$ $1229.50,18,10,27.9475,-82.4448,168,82,99.9$ $1234.50,18,10,27.9475,-82.4448,165,82,99.9$ $1239.50,18,10,27.9475,-82.4448,162,82,99.9$ $1244.50,18,10,27.9475,-82.4448,159,82,99.9$ $1249.50,18,10,27.9475,-82.4448,156,82,99.9$ $1254.50,18,10,27.9475,-82.4448,152,82,99.9$ $1259.50,18,10,27.9475,-82.4448,149,82,99.9$ $1264.50,18,10,27.9475,-82.4448,145,81,99.9$ $1269.50,18,10,27.9475,-82.4448,141,81,99.9$ $1274.50,18,10,27.9475,-82.4448,137,81,99.9$ $1279.50,18,10,27.9475,-82.4448,133,81,99.9$ $1284.50,18,10,27.9475,-82.4448,129,81,99.9$ $1289.50,18,10,27.9475,-82.4448,125,81,99.9$ $1294.50,18,10,27.9475,-82.4448,121,81,99.9$ $1299.50,18,10,27.9475,-82.4448,117,81,99.9$ $1304.50,18,10,27.9475,-82.4448,113,82,99.9$ $1309.50,18,10,27.9475,-82.4448,110,82,99.9$ $1314.50,18,10,27.9475,-82.4448,106,82,99.9$ $1319.50,18,10,27.9475,-82.4448,103,82,99.9$ $1324.50,18,10,27.9475,-82.4448,99,83,99.9$

$1329.50,18,10,27.9475,-82.4448,96,83,99.9$

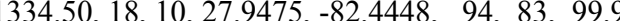
$1339.50,18,10,27.9475,-82.4448,91,84,99.9$ $1344.50,18,10,27.9475,-82.4448,89,84,99.9$ $1349.50,18,10,27.9475,-82.4448,86,84,99.9$ $1354.50,18,10,27.9475,-82.4448,84,84,99.9$ $1359.50,18,10,27.9475,-82.4448,83,84,99.9$ $1364.50,18,10,27.9475,-82.4448,81,83,99.9$ $1369.50,18,10,27.9475,-82.4448,80,83,99.9$ $1374.50,18,10,27.9475,-82.4448,78,82,-1.9$ $1379.50,18,10,27.9475,-82.4448,77,82,-1.9$ $1384.50,18,10,27.9475,-82.4448,76,81,-1.8$ $1389.50,18,10,27.9475,-82.4448,75,81,-1.6$ $1394.50,18,10,27.9475,-82.4448,75,80,-1.4$ $1399.50,18,10,27.9475,-82.4448,74,79,-1.1$ $1404.50,18,10,27.9475,-82.4448,73,78,-0.8$ $1409.50,18,10,27.9475,-82.4448,73,77,-0.4$ $1414.50,18,10,27.9475,-82.4448,72,76,0.0$ $1419.50,18,10,27.9475,-82.4448,72,75,0.5$ $1424.50,18,10,27.9475,-82.4448,72,74,0.9$ $1429.50,18,10,27.9475,-82.4448,71,73,1.2$
$1434.50,18,10,27.9475,-82.4448,71,72,1.4$ $1439.50,18,10,27.9475,-82.4448,71,74,1.6$ $1444.50,18,10,27.9475,-82.4448,71,73,1.7$ $1449.50,18,10,27.9475,-82.4448,70,73,1.9$ $1454.50,18,10,27.9475,-82.4448,69,72,2.0$ $1459.50,18,10,27.9475,-82.4448,68,72,2.2$ $1464.50,18,10,27.9475,-82.4448,67,71,2.3$ $1469.50,18,10,27.9475,-82.4448,67,70,2.5$ $1474.50,18,10,27.9475,-82.4448,66,70,2.6$ $1479.50,18,10,27.9475,-82.4448,65,69,2.7$ $1484.50,18,10,27.9475,-82.4448,65,68,2.8$ $1489.50,18,10,27.9475,-82.4448,64,68,2.8$ $1494.50,18,10,27.9475,-82.4448,63,67,2.9$ $1499.50,18,10,27.9475,-82.4448,63,67,2.9$ $1504.50,18,10,27.9475,-82.4448,62,66,3.0$ $1509.50,18,10,27.9475,-82.4448,62,65, \quad 3.0$ $1514.50,18,10,27.9475,-82.4448,61,65,3.1$ $1519.50,18,10,27.9475,-82.4448,60,64,3.1$ $1524.50,18,10,27.9475,-82.4448,60,64,3.1$ $1529.50,18,10,27.9475,-82.4448,59,63,3.2$ $1534.50,18,10,27.9475,-82.4448,59,62,3.2$ $1539.50,18,10,27.9475,-82.4448,58,62,3.2$ $1544.50,18,10,27.9475,-82.4448,57,61,3.2$ $1549.50,18,10,27.9475,-82.4448,57,60,3.2$ $1554.50,18,10,27.9475,-82.4448,56,60,3.2$ $1559.50,18,10,27.9475,-82.4448,56,59,3.2$ $1564.50,18,10,27.9475,-82.4448,55,58,3.3$ $1569.50,18,10,27.9475,-82.4448,55,58, \quad 3.3$ $1574.50,18,10,27.9475,-82.4448,54,57,3.3$ $1579.50,18,10,27.9475,-82.4448,54,57,3.3$ $1584.50,18,10,27.9475,-82.4448,54,56,3.3$ $1589.50,18,10,27.9475,-82.4448, \quad 53,55, \quad 3.3$ $1594.50,18,10,27.9475,-82.4448,53,55,3.3$ $1599.50,18,10,27.9475,-82.4448,52,54,3.3$ $1604.50,18,10,27.9475,-82.4448,52,54,3.3$ $1609.50,18,10,27.9475,-82.4448,51,53,3.3$ $1614.50,18,10,27.9475,-82.4448,51,53,3.2$ $1619.50,18,10,27.9475,-82.4448,51,52,3.2$ $1624.50,18,10,27.9475,-82.4448,51,52,3.2$ $1629.50,18,10,27.9475,-82.4448,50,51,3.2$ $1634.50,18,10,27.9475,-82.4448,50,51,3.2$ $1639.50,18,10,27.9475,-82.4448,50,50,3.2$ $1644.50,18,10,27.9475,-82.4448,49,50,3.1$ $1649.50,18,10,27.9475,-82.4448,49,49,3.1$ $1654.50,18,10,27.9475,-82.4448,48,49,3.1$
$1659.50,18,10,27.9475,-82.4448,48,48,3.1$ $1664.50,18,10,27.9475,-82.4448,48,48,3.1$ $1669.50,18,10,27.9475,-82.4448,47,47,3.1$ $1674.50,18,10,27.9475,-82.4448,47,47,3$. $679.50,18,10,27.9475,-82.4448,46,47,3.0$ $1684.50,18,10,27.9475,-82.4448,46,46,3.0$ $1689.50,18,10,27.9475,-82.4448,46,46,3.0$ $1694.50,18,10,27.9475,-82.4448,46,45,3.0$ $1699.50,18,10,27.9475,-82.4448,45,45,3.0$ $1704.50,18,10,27.9475,-82.4448,45,44,3.0$ $1709.50,18,10,27.9475,-82.4448,45,44,2.9$ $1714.50,18,10,27.9475,-82.4448,44,44,2.9$ $1719.50,18,10,27.9475,-82.4448,44,43,2.9$ $1724.50,18,10,27.9475,-82.4448,44,43,2.9$ $1729.50,18,10,27.9475,-82.4448,44,42,2.9$ $1734.50,18,10,27.9475,-82.4448,43,42,2.8$ $1739.50,18,10,27.9475,-82.4448,43,42,2.8$ $1744.50,18,10,27.9475,-82.4448,43,41,2.8$ $1749.50,18,10,27.9475,-82.4448,42,41,2.8$ $1754.50,18,10,27.9475,-82.4448,42,41,2.8$ $1759.50,18,10,27.9475,-82.4448,42,40,2.7$ $1764.50,18,10,27.9475,-82.4448,42,40,2.7$ $1769.50,18,10,27.9475,-82.4448,41,40,2.7$ $1774.50,18,10,27.9475,-82.4448,41,39,2.7$ $1779.50,18,10,27.9475,-82.4448,41,39,2.6$ $1784.50,18,10,27.9475,-82.4448,41,39,2.6$ $1789.50,18,10,27.9475,-82.4448,40,38,2.6$ $1794.50,18,10,27.9475,-82.4448,40,38,2.6$ $1799.50,18,10,27.9475,-82.4448,40,38,2.5$ $1804.50,18,10,27.9475,-82.4448,40,37,2.5$ $1809.50,18,10,27.9475,-82.4448,40,37,2.5$ $1814.50,18,10,27.9475,-82.4448,39,37,2.5$ $1819.50,18,10,27.9475,-82.4448,39,36,2.4$ $1824.50,18,10,27.9475,-82.4448,39,36,2.4$ $1829.50,18,10,27.9475,-82.4448,39,36,2.4$ $1834.50,18,10,27.9475,-82.4448,38,35,2.3$ $1839.50,18,10,27.9475,-82.4448,38,35,2.3$ $1844.50,18,10,27.9475,-82.4448,38,35,2.3$ $1849.50,18,10,27.9475,-82.4448,38,34,2.3$ $1854.50,18,10,27.9475,-82.4448,37,34,2.2$ $1859.50,18,10,27.9475,-82.4448,37,34,2.2$ $1864.50,18,10,27.9475,-82.4448,37,34,2.2$ $1869.50,18,10,27.9475,-82.4448,37,33,2.2$ $1874.50,18,10,27.9475,-82.4448,36,33,2.1$ $1879.50,18,10,27.9475,-82.4448,36,33,2.1$ 
$1884.50,18,10,27.9475,-82.4448,36,33,2.1$ $1889.50,18,10,27.9475,-82.4448,36,32,2.1$ $1894.50,18,10,27.9475,-82.4448,35,32,2.0$ $1899.50,18,10,27.9475,-82.4448,35,32,2.0$ $1904.50,18,10,27.9475,-82.4448,35,31,2.0$ $1909.50,18,10,27.9475,-82.4448,35,31,2.0$ $1914.50,18,10,27.9475,-82.4448,35,31,1.9$ $1919.50,18,10,27.9475,-82.4448,34,31,1.9$ $1924.50,18,10,27.9475,-82.4448,34,30,1.9$ $1929.50,18,10,27.9475,-82.4448,34,30,1.9$ $1934.50,18,10,27.9475,-82.4448,34,30,1.8$ $1939.50,18,10,27.9475,-82.4448,34,30,1.8$ $1944.50,18,10,27.9475,-82.4448,33,29,1.8$ $1949.50,18,10,27.9475,-82.4448,33,29,1.8$ $1954.50,18,10,27.9475,-82.4448,33,29,1.7$ $1959.50,18,10,27.9475,-82.4448, \quad 33,29,1.7$ $1964.50,18,10,27.9475,-82.4448,33,28,1.7$ $1969.50,18,10,27.9475,-82.4448,33,28,1.7$ $1974.50,18,10,27.9475,-82.4448,32,28,1.6$ $1979.50,18,10,27.9475,-82.4448,32,28,1.6$ $1984.50,18,10,27.9475,-82.4448,32,28,1.6$ $1989.50,18,10,27.9475,-82.4448,32,28,1.6$ $1994.50,18,10,27.9475,-82.4448,32,27, \quad 1.6$ $1999.50,18,10,27.9475,-82.4448,32,27,1.5$ $2004.50,18,10,27.9475,-82.4448,31,27, \quad 1.5$ $2009.50,18,10,27.9475,-82.4448,31,27,1.5$ $2014.50,18,10,27.9475,-82.4448,31,27,1.5$ $2019.50,18,10,27.9475,-82.4448,31,26,1.5$ $2024.50,18,10,27.9475,-82.4448, \quad 31,26,1.5$ $2029.50,18,10,27.9475,-82.4448,31,26,1.4$ $2034.50,18,10,27.9475,-82.4448,30,26,1.4$ $2039.50,18,10,27.9475,-82.4448,30,25,1.4$ $2044.50,18,10,27.9475,-82.4448,30,25,1.4$ $2049.50,18,10,27.9475,-82.4448,30,25,1.4$ $2054.50,18,10,27.9475,-82.4448,30,25,1.4$ $2059.50,18,10,27.9475,-82.4448,30,25,1.4$ $2064.50,18,10,27.9475,-82.4448,30,25,1.3$ $2069.50,18,10,27.9475,-82.4448,29,24,1.3$ $2074.50,18,10,27.9475,-82.4448,29,24,1.3$ $2079.50,18,10,27.9475,-82.4448,29,24,1.3$ $2084.50,18,10,27.9475,-82.4448,29,24,1.3$ $2089.50,18,10,27.9475,-82.4448,29,24,1.3$ $2094.50,18,10,27.9475,-82.4448,29,24,1.3$ $2099.50,18,10,27.9475,-82.4448,28,24,1.3$ $2104.50,18,10,27.9475,-82.4448,28,23,1.2$
$2109.50,18,10,27.9475,-82.4448,28,23,1.2$ $2114.50,18,10,27.9475,-82.4448,28,23,1.2$ $2119.50,18,10,27.9475,-82.4448,28,23,1.2$ $2124.50,18,10,27.9475,-82.4448,28,23,1.2$ $2129.50,18,10,27.9475,-82.4448,27,23,1.2$ $2134.50,18,10,27.9475,-82.4448,27,22,1.2$ $2139.50,18,10,27.9475,-82.4448,27,22,1.2$ $2144.50,18,10,27.9475,-82.4448,27,22,1.1$ $2149.50,18,10,27.9475,-82.4448,27,22,1.1$ $2154.50,18,10,27.9475,-82.4448,27,22,1.1$ $2159.50,18,10,27.9475,-82.4448,28,22,1.1$ $2164.50,18,10,27.9475,-82.4448,27,22,1.1$ $2169.50,18,10,27.9475,-82.4448,27,22,1.1$ $2174.50,18,10,27.9475,-82.4448,27,21,1.1$ $2179.50,18,10,27.9475,-82.4448,27,21,1.1$ $2184.50,18,10,27.9475,-82.4448,27,21,1.1$ $2189.50,18,10,27.9475,-82.4448,27,21,1.1$ $2194.50,18,10,27.9475,-82.4448,26,21,1.0$ $2199.50,18,10,27.9475,-82.4448,26,21,1.0$ $2204.50,18,10,27.9475,-82.4448,26,21,1.0$ $2209.50,18,10,27.9475,-82.4448,26,21,1.0$ $2214.50,18,10,27.9475,-82.4448,26,20,1.0$ $2219.50,18,10,27.9475,-82.4448,25,20,1.0$ $2224.50,18,10,27.9475,-82.4448,25,20,1.0$ $2229.50,18,10,27.9475,-82.4448,25,20,1.0$ $2234.50,18,10,27.9475,-82.4448,25,20,1.0$ $2239.50,18,10,27.9475,-82.4448,25,20,1.0$ $2244.50,18,10,27.9475,-82.4448,25,20,1.0$ $2249.50,18,10,27.9475,-82.4448,24,20,0.9$ $2254.50,18,10,27.9475,-82.4448,24,20,0.9$ $2259.50,18,10,27.9475,-82.4448,24,19,0.9$ $2264.50,18,10,27.9475,-82.4448,24,19,0.9$ $2269.50,18,10,27.9475,-82.4448,24,19,0.9$ $2274.50,18,10,27.9475,-82.4448,24,19,0.9$ $2279.50,18,10,27.9475,-82.4448,24,19,0.9$ $2284.50,18,10,27.9475,-82.4448,24,19,0.9$ $2289.50,18,10,27.9475,-82.4448,24,19,0.9$ $2294.50,18,10,27.9475,-82.4448,24,19,0.9$ $2299.50,18,10,27.9475,-82.4448,23,19, \quad 0.8$ $2304.50,18,10,27.9475,-82.4448,23,18, \quad 0.8$ $2309.50,18,10,27.9475,-82.4448,23,18,0.8$ $2314.50,18,10,27.9475,-82.4448,23,18,0.8$ $2319.50,18,10,27.9475,-82.4448,23,18,0.8$ $2324.50,18,10,27.9475,-82.4448,23,18,0.8$ $2329.50,18,10,27.9475,-82.4448,23,18,0.8$
$2334.50,18,10,27.9475,-82.4448,23,18,0.8$ $2339.50,18,10,27.9475,-82.4448,22,18,0.8$ $2344.50,18,10,27.9475,-82.4448,22,18,0.8$ $2349.50,18,10,27.9475,-82.4448,22,18,0.7$ $2354.50,18,10,27.9475,-82.4448,22,18,0.7$ $2359.50,18,10,27.9475,-82.4448,22,17,0.7$ $2364.50,18,10,27.9475,-82.4448,22,17,0.7$ $2369.50,18,10,27.9475,-82.4448,21,17,0.7$ $2374.50,18,10,27.9475,-82.4448,21,17,0.7$ $2379.50,18,10,27.9475,-82.4448,21,17,0.7$ $2384.50,18,10,27.9475,-82.4448,21,17,0.7$ $2389.50,18,10,27.9475,-82.4448,21,17,0.7$ $2394.50,18,10,27.9475,-82.4448,21,17,0.7$ $2399.50,18,10,27.9475,-82.4448,21,17,0.7$ $2404.50,18,10,27.9475,-82.4448,21,17,0.7$ $2409.50,18,10,27.9475,-82.4448,21,17,0.7$ $2414.50,18,10,27.9475,-82.4448,21,16,0.7$ $2419.50,18,10,27.9475,-82.4448,21,16,0.6$ $2424.50,18,10,27.9475,-82.4448,21,16,0.6$ $2429.50,18,10,27.9475,-82.4448,20,16,0.6$ $2434.50,18,10,27.9475,-82.4448,20,16,0.6$ $2439.50,18,10,27.9475,-82.4448,20,16,0.6$ $2444.50,18,10,27.9475,-82.4448,20,16,0.6$ $2449.50,18,10,27.9475,-82.4448,20,16,0.6$ $2454.50,18,10,27.9475,-82.4448,20,16,0.6$ $2459.50,18,10,27.9475,-82.4448,19,16,0.6$ $2464.50,18,10,27.9475,-82.4448,19,16,0.6$ $2469.50,18,10,27.9475,-82.4448,19,16,0.6$ $2474.50,18,10,27.9475,-82.4448,19,16,0.6$ $2479.50,18,10,27.9475,-82.4448,19,15,0.6$ $2484.50,18,10,27.9475,-82.4448,19,15,0.6$ $2489.50,18,10,27.9475,-82.4448,19,15,0.6$ $2494.50,18,10,27.9475,-82.4448,19,15,0.6$ $2499.50,18,10,27.9475,-82.4448,19,15,0.6$ $2504.50,18,10,27.9475,-82.4448,19,15,0.6$ $2509.50,18,10,27.9475,-82.4448,18,15,0.6$ $2514.50,18,10,27.9475,-82.4448,18,15,0.6$ $2519.50,18,10,27.9475,-82.4448,19,15,0.6$ $2524.50,18,10,27.9475,-82.4448,19,15,0.6$ $2529.50,18,10,27.9475,-82.4448,19,15,0.6$ $2534.50,18,10,27.9475,-82.4448,19,15,0.6$ $2539.50,18,10,27.9475,-82.4448,19,15,0.6$ $2544.50,18,10,27.9475,-82.4448,18,15,0.6$ $2549.50,18,10,27.9475,-82.4448,18,15,0.6$ $2554.50,18,10,27.9475,-82.4448,18,15,0.5$ 
$2559.50,18,10,27.9475,-82.4448,18,15, \quad 0.5$ $2564.50,18,10,27.9475,-82.4448,18,14,0.5$ $2569.50,18,10,27.9475,-82.4448,18,14,0.5$ $2574.50,18,10,27.9475,-82.4448,18,14,0.5$ $2579.50,18,10,27.9475,-82.4448,17,14,0.5$ $2584.50,18,10,27.9475,-82.4448,17,14,0.5$ $2589.50,18,10,27.9475,-82.4448,17,14,0.5$ $2594.50,18,10,27.9475,-82.4448,17,14,0.5$ $2599.50,18,10,27.9475,-82.4448,17,14,0.5$ $2604.50,18,10,27.9475,-82.4448,17,14,0.5$ $2609.50,18,10,27.9475,-82.4448,17,14, \quad 0.5$ $2614.50,18,10,27.9475,-82.4448,16,14,0.5$ $2619.50,18,10,27.9475,-82.4448,16,14,0.5$ $2624.50,18,10,27.9475,-82.4448,16,14,0.5$ $2629.50,18,10,27.9475,-82.4448,16,13,0.5$ $2634.50,18,10,27.9475,-82.4448,16,13,0.5$ $2639.50,18,10,27.9475,-82.4448,16,13,0.5$ $2644.50,18,10,27.9475,-82.4448,16,13,0.5$ $2649.50,18,10,27.9475,-82.4448,16,13,0.5$ $2654.50,18,10,27.9475,-82.4448,16,13,0.5$ $2659.50,18,10,27.9475,-82.4448,16,13,0.5$ $2664.50,18,10,27.9475,-82.4448,16,13,0.4$ $2669.50,18,10,27.9475,-82.4448,16,13,0.4$ $2674.50,18,10,27.9475,-82.4448,15,13,0.4$ $2679.50,18,10,27.9475,-82.4448,15,13,0.4$ $2684.50,18,10,27.9475,-82.4448,15,13,0.4$ $2689.50,18,10,27.9475,-82.4448,15,13,0.4$ $2694.50,18,10,27.9475,-82.4448,15,13,0.4$ $2699.50,18,10,27.9475,-82.4448,15,13,0.4$ $2704.50,18,10,27.9475,-82.4448,15,13,0.4$ $2709.50,18,10,27.9475,-82.4448,15,13,0.4$ $2714.50,18,10,27.9475,-82.4448,15,13,0.4$ $2719.50,18,10,27.9475,-82.4448,14,12,0.4$ $2724.50,18,10,27.9475,-82.4448,14,12,0.4$ $2729.50,18,10,27.9475,-82.4448,14,12,0.4$ $2734.50,18,10,27.9475,-82.4448,14,12,0.4$ $2739.50,18,10,27.9475,-82.4448,14,12,0.4$ $2744.50,18,10,27.9475,-82.4448,14,12,0.4$ $2749.50,18,10,27.9475,-82.4448,14,12,0.4$ $2754.50,18,10,27.9475,-82.4448,14,12,0.4$ $2759.50,18,10,27.9475,-82.4448,14,12,0.4$ $2764.50,18,10,27.9475,-82.4448,14,12,0.4$ $2769.50,18,10,27.9475,-82.4448,14,12,0.4$ $2774.50,18,10,27.9475,-82.4448,14,12,0.4$ $2779.50,18,10,27.9475,-82.4448,14,12,0.4$
$2784.50,18,10,27.9475,-82.4448,14,12,0.4$ $2789.50,18,10,27.9475,-82.4448,14,12,0.4$ $2794.50,18,10,27.9475,-82.4448,14,12,0.4$ $2799.50,18,10,27.9475,-82.4448,14,12,0.3$ $2804.50,18,10,27.9475,-82.4448,14,11,0.3$ $2809.50,18,10,27.9475,-82.4448,13,11,0.3$ $2814.50,18,10,27.9475,-82.4448,13,11,0.3$ $2819.50,18,10,27.9475,-82.4448,13,11,0.3$ $2824.50,18,10,27.9475,-82.4448,13,11,0.3$ $2829.50,18,10,27.9475,-82.4448,13,11,0.3$ $2834.50,18,10,27.9475,-82.4448,13,11,0.3$ $2839.50,18,10,27.9475,-82.4448,13,11,0.3$ $2844.50,18,10,27.9475,-82.4448,13,11,0.3$ $2849.50,18,10,27.9475,-82.4448,13,11,0.3$ $2854.50,18,10,27.9475,-82.4448,13,11,0.3$ $2859.50,18,10,27.9475,-82.4448,12,11,0.3$ $2864.50,18,10,27.9475,-82.4448,12,11,0.3$ $2869.50,18,10,27.9475,-82.4448,12,11,0.3$ $2874.50,18,10,27.9475,-82.4448,12,11,0.3$ $2879.50,18,10,27.9475,-82.4448,14,11,0.3$ $2884.50,18,10,27.9475,-82.4448,14,11,0.3$ $2889.50,18,10,27.9475,-82.4448,14,11,0.3$ $2894.50,18,10,27.9475,-82.4448,14,11,0.3$ $2899.50,18,10,27.9475,-82.4448,13,11,0.3$ $2904.50,18,10,27.9475,-82.4448,13,11,0.3$ $2909.50,18,10,27.9475,-82.4448,13,11,0.3$ $2914.50,18,10,27.9475,-82.4448,13,11,0.3$ $2919.50,18,10,27.9475,-82.4448,13,11,0.3$ $2924.50,18,10,27.9475,-82.4448,13,10,0.3$ $2929.50,18,10,27.9475,-82.4448,13,10,0.3$ $2934.50,18,10,27.9475,-82.4448,13,10,0.3$ $2939.50,18,10,27.9475,-82.4448,12,10,0.3$ $2944.50,18,10,27.9475,-82.4448,12,10,0.3$ $2949.50,18,10,27.9475,-82.4448,12,10,0.3$ $2954.50,18,10,27.9475,-82.4448,12,10,0.3$ $2959.50,18,10,27.9475,-82.4448,12,10, \quad 0.3$ $2964.50,18,10,27.9475,-82.4448,12,10,0.3$ $2969.50,18,10,27.9475,-82.4448,12,10,0.3$ $2974.50,18,10,27.9475,-82.4448,12,10,0.3$ $2979.50,18,10,27.9475,-82.4448,12,10,0.3$ $2984.50,18,10,27.9475,-82.4448,12,10,0.3$ $2989.50,18,10,27.9475,-82.4448,12,10,0.3$ $2994.50,18,10,27.9475,-82.4448,11,10,0.3$ $2999.50,18,10,27.9475,-82.4448,12,10,0.3$ $3004.50,18,10,27.9475,-82.4448,11,10,0.3$
$3009.50,18,10,27.9475,-82.4448,11,10,0.2$ $3014.50,18,10,27.9475,-82.4448,11,10,0.2$ $3019.50,18,10,27.9475,-82.4448,11,10,0.2$ $3024.50,18,10,27.9475,-82.4448,11,10,0.2$ $3029.50,18,10,27.9475,-82.4448,11,10,0.2$ $3034.50,18,10,27.9475,-82.4448,11,10,0.2$ $3039.50,18,10,27.9475,-82.4448,11,10,0.2$ $3044.50,18,10,27.9475,-82.4448,11,10,0.2$ $3049.50,18,10,27.9475,-82.4448,11,9,0.2$ $3054.50,18,10,27.9475,-82.4448,11,9,0.2$ $3059.50,18,10,27.9475,-82.4448, \quad 10,9, \quad 0.2$ $3064.50,18,10,27.9475,-82.4448,10,9,0.2$ $3069.50,18,10,27.9475,-82.4448,10,9,0.2$ $3074.50,18,10,27.9475,-82.4448, \quad 10,9, \quad 0.2$ $3079.50,18,10,27.9475,-82.4448,10,9, \quad 0.2$ $3084.50,18,10,27.9475,-82.4448,10,9, \quad 0.2$ $3089.50,18,10,27.9475,-82.4448,10,9,0.2$ $3094.50,18,10,27.9475,-82.4448, \quad 10,9, \quad 0.2$ $3099.50,18,10,27.9475,-82.4448,10,9,0.2$ $3104.50,18,10,27.9475,-82.4448,10,9, \quad 0.2$ $3109.50,18,10,27.9475,-82.4448,10,9,0.2$ $3114.50,18,10,27.9475,-82.4448, \quad 10,9, \quad 0.2$ $3119.50,18,10,27.9475,-82.4448,9,9,0.2$ $3124.50,18,10,27.9475,-82.4448,9,9,0.2$ $3129.50,18,10,27.9475,-82.4448, \quad 9, \quad 9, \quad 0.2$ $3134.50,18,10,27.9475,-82.4448,9, \quad 9, \quad 0.2$ $3139.50,18,10,27.9475,-82.4448, \quad 9,9, \quad 0.2$ $3144.50,18,10,27.9475,-82.4448,9,9, \quad 0.2$ $3149.50,18,10,27.9475,-82.4448, \quad 9, \quad 9,0.2$ $3154.50,18,10,27.9475,-82.4448,9,9,0.2$ $3159.50,18,10,27.9475,-82.4448,9, \quad 9, \quad 0.2$ $3164.50,18,10,27.9475,-82.4448, \quad 9, \quad 9,0.2$ $3169.50,18,10,27.9475,-82.4448,9,9,0.2$ $3174.50,18,10,27.9475,-82.4448,9,9,0.2$ $3179.50,18,10,27.9475,-82.4448, \quad 8,9,0.2$ $3184.50,18,10,27.9475,-82.4448, \quad 8, \quad 9, \quad 0.2$ $3189.50,18,10,27.9475,-82.4448, \quad 8,9,0.2$ $3194.50,18,10,27.9475,-82.4448, \quad 8, \quad 8,0.2$ $3199.50,18,10,27.9475,-82.4448, \quad 8,8,0.2$ $3204.50,18,10,27.9475,-82.4448, \quad 8, \quad 8,0.2$ $3209.50,18,10,27.9475,-82.4448, \quad 8, \quad 8,0.2$ $3214.50,18,10,27.9475,-82.4448, \quad 8,8,0.2$ $3219.50,18,10,27.9475,-82.4448, \quad 8,8, \quad 0.2$ $3224.50,18,10,27.9475,-82.4448, \quad 8, \quad 8, \quad 0.2$ $3229.50,18,10,27.9475,-82.4448, \quad 8, \quad 8, \quad 0.2$ 
$3234.50,18,10,27.9475,-82.4448, \quad 8, \quad 8, \quad 0.2$ $3239.50,18,10,27.9475,-82.4448, \quad 8, \quad 8,0.2$ $3244.50,18,10,27.9475,-82.4448, \quad 8, \quad 8, \quad 0.2$ $3249.50,18,10,27.9475,-82.4448, \quad 8, \quad 8, \quad 0.2$ $3254.50,18,10,27.9475,-82.4448, \quad 8, \quad 8, \quad 0.2$ $3259.50,18,10,27.9475,-82.4448, \quad 8,8,0.2$ $3264.50,18,10,27.9475,-82.4448, \quad 8, \quad 8, \quad 0.2$ $3269.50,18,10,27.9475,-82.4448, \quad 8, \quad 8, \quad 0.2$ $3274.50,18,10,27.9475,-82.4448, \quad 8, \quad 8, \quad 0.2$ $3279.50,18,10,27.9475,-82.4448, \quad 8, \quad 8, \quad 0.2$ $3284.50,18,10,27.9475,-82.4448, \quad 8, \quad 8, \quad 0.2$ $3289.50,18,10,27.9475,-82.4448, \quad 8,8,0.2$ $3294.50,18,10,27.9475,-82.4448, \quad 7, \quad 8,0.2$ $3299.50,18,10,27.9475,-82.4448, \quad 7, \quad 8, \quad 0.2$ $3304.50,18,10,27.9475,-82.4448, \quad 7, \quad 8, \quad 0.2$ $3309.50,18,10,27.9475,-82.4448, \quad 7, \quad 8,0.2$ $3314.50,18,10,27.9475,-82.4448, \quad 7, \quad 8,0.2$ $3319.50,18,10,27.9475,-82.4448, \quad 7, \quad 8,0.1$ $3324.50,18,10,27.9475,-82.4448, \quad 7, \quad 8,0.1$ $3329.50,18,10,27.9475,-82.4448, \quad 7, \quad 8,0.1$ $3334.50,18,10,27.9475,-82.4448, \quad 7, \quad 8, \quad 0.1$ $3339.50,18,10,27.9475,-82.4448, \quad 7, \quad 8, \quad 0.1$

$3344.50,18,10,27.9475,-82.4448, \quad 7, \quad 8,0.1$ $3349.50,18,10,27.9475,-82.4448, \quad 7, \quad 8,0.1$ $3354.50,18,10,27.9475,-82.4448, \quad 7, \quad 8,0.1$ $3359.50,18,10,27.9475,-82.4448, \quad 6, \quad 8, \quad 0.1$ $3364.50,18,10,27.9475,-82.4448, \quad 6, \quad 8,0.1$ $3369.50,18,10,27.9475,-82.4448, \quad 6, \quad 8, \quad 0.1$ $3374.50,18,10,27.9475,-82.4448, \quad 6, \quad 7, \quad 0.1$
$3379.50,18,10,27.9475,-82.4448, \quad 6, \quad 7,0.1$ $3384.50,18,10,27.9475,-82.4448,6,7,0.1$ $3389.50,18,10,27.9475,-82.4448,6,7,0.1$ $3394.50,18,10,27.9475,-82.4448, \quad 6, \quad 7, \quad 0.1$ $3399.50,18,10,27.9475,-82.4448,6,7,0.1$ $3404.50,18,10,27.9475,-82.4448, \quad 6, \quad 7,0.1$ $3409.50,18,10,27.9475,-82.4448,6,7,0$. $3414.50,18,10,27.9475,-82.4448, \quad 6, \quad 7, \quad 0.1$ $3419.50,18,10,27.9475,-82.4448,5,7,0.1$ $3424.50,18,10,27.9475,-82.4448, \quad 5,7,0.1$ $3429.50,18,10,27.9475,-82.4448, \quad 5,7,0$. $3434.50,18,10,27.9475,-82.4448,5,7,0.1$ $3439.50,18,10,27.9475,-82.4448, \quad 5,7,0$. $3444.50,18,10,27.9475,-82.4448, \quad 5,7,0.1$ $3449.50,18,10,27.9475,-82.4448, \quad 5, \quad 7, \quad 0.1$ $3454.50,18,10,27.9475,-82.4448,5,7,0.1$ $3459.50,18,10,27.9475,-82.4448, \quad 5,7,0.1$ $3464.50,18,10,27.9475,-82.4448,5,7,0$. $3469.50,18,10,27.9475,-82.4448,5,7,0.1$ $3474.50,18,10,27.9475,-82.4448, \quad 5,7,0.1$ $3479.50,18,10,27.9475,-82.4448, \quad 5,7,0$. $3484.50,18,10,27.9475,-82.4448, \quad 5, \quad 7,0.1$ $3489.50,18,10,27.9475,-82.4448, \quad 5,7,0.1$ $3494.50,18,10,27.9475,-82.4448,5,7,0$. $3499.50,18,10,27.9475,-82.4448, \quad 4,7,0$. $3504.50,18,10,27.9475,-82.4448, \quad 4, \quad 7,0.1$ $3509.50,18,10,27.9475,-82.4448, \quad 4,7,0.1$ $3514.50,18,10,27.9475,-82.4448, \quad 4, \quad 7, \quad 0.1$ $3519.50,18,10,27.9475,-82.4448, \quad 4,7,0$.
$3524.50,18,10,27.9475,-82.4448, \quad 4, \quad 7,0.1$ $3529.50,18,10,27.9475,-82.4448, \quad 4, \quad 7,0.1$ $3534.50,18,10,27.9475,-82.4448, \quad 4, \quad 7,0.1$ $3539.50,18,10,27.9475,-82.4448, \quad 4,7,0.1$ $3544.50,18,10,27.9475,-82.4448,4,7,0.1$ $3549.50,18,10,27.9475,-82.4448, \quad 4, \quad 7, \quad 0.1$ $3554.50,18,10,27.9475,-82.4448, \quad 4,7,0.1$ $3559.50,18,10,27.9475,-82.4448, \quad 4, \quad 7,0.1$ $3564.50,18,10,27.9475,-82.4448, \quad 4,7,0.1$ $3569.50,18,10,27.9475,-82.4448, \quad 4, \quad 7,0.1$ $3574.50,18,10,27.9475,-82.4448,4, \quad 7,0$. $3579.50,18,10,27.9475,-82.4448,4,7,0.1$ $3584.50,18,10,27.9475,-82.4448, \quad 4,7,0.1$ $3589.50,18,10,27.9475,-82.4448, \quad 4,6,0$. $3594.50,18,10,27.9475,-82.4448, \quad 3,6,0.1$ $3599.50,18,10,27.9475,-82.4448,6, \quad 6,0.1$ $3604.50,18,10,27.9475,-82.4448,6,6,0.1$ $3609.50,18,10,27.9475,-82.4448, \quad 6,6, \quad 0.1$ $3614.50,18,10,27.9475,-82.4448,6, \quad 6,0.1$ $3619.50,18,10,27.9475,-82.4448,6,6,0.1$ $3624.50,18,10,27.9475,-82.4448, \quad 5, \quad 6,0.1$ $3629.50,18,10,27.9475,-82.4448, \quad 5,6,0.1$ $3634.50,18,10,27.9475,-82.4448, \quad 5,6,0.1$ $3639.50,18,10,27.9475,-82.4448, \quad 5,6,0.1$ $3644.50,18,10,27.9475,-82.4448, \quad 5,6, \quad 0.1$ $3649.50,18,10,27.9475,-82.4448, \quad 5, \quad 6,0.1$ $3654.50,18,10,27.9475,-82.4448, \quad 5,6,0.1$ $3659.50,18,10,27.9475,-82.4448,-3,5,0.1$ 


\section{Appendix C \\ Alternative Methods for Estimating Joint Probability of EXCEEDANCE AND MEAN RECURRENCE INTERVAL}

\section{B.1 ESTIMATES CORRESPONDING TO SAMPLE EVENT SPACE SE2}

The members of the sample space SE2 are defined by pairs of maximum wind speed in each hurricane and the largest of the storm surge heights associated with that speed, and pairs of the maximum storm surge height in each hurricane and the largest of the wind speeds associated with that height. We now make this definition more precise. Consider hurricane $h_{i}$. Associated with each $j$ (i.e., at each time $t_{j}$ ) are a wind speed $v_{i j}$ and a storm surge height $s_{i j}$. The wind speed variate being selected as a basis for the subsequent estimates is the maximum wind speed in each hurricane, denoted by $v_{i}^{(1)} \equiv \max _{\mathrm{j}}\left(v_{i j}\right)$. There may be several times $j$ at which the same value $v_{i}^{(1)}$ occurs. The storm surge height $s_{i}{ }^{(1)}$ associated with the value $v_{i}^{(1)}$ is selected to be the largest of the storm surge heights occurring at any of those times. The pair, belonging to hurricane $h_{i}$, selected for incorporation in the data sample of size $n$ used for our estimates is $v_{i}^{(1)}, s_{i}{ }^{(1)}$ (the explanation for our use of the superscript (1) will become clear forthwith). The following is an example of rank ordered pairs of wind speed and storm surge height data in a hurricane $h_{i}$ :

$\begin{array}{cl}\begin{array}{c}\boldsymbol{v}_{\boldsymbol{i}, \max } \\ (1-\mathrm{minute} \mathrm{m} / \mathrm{s})\end{array} & \begin{array}{l}\boldsymbol{s}_{\boldsymbol{i}, \max } \\ (\mathrm{m})\end{array} \\ 70 & 6 \\ 70 & 5.5 \\ 68 & 6 \\ 68 & 5.8 \\ 68 & 5.3 \\ 65 & 5.5 \\ 65 & 4.7 \\ 60 & 5.0 \\ 55 & 5.2 \\ 55 & 4.5 \\ \ldots & \ldots \\ \cdots & \ldots\end{array}$

where $v_{i}^{(1)} \equiv \max _{j}\left(v_{i j}\right)=70 \mathrm{~m} / \mathrm{s}(156 \mathrm{mph})$. The pair selected for incorporation in the data sample is $v_{i}^{(1)}, s_{i}^{(1)}$ or, in our example, $70 \mathrm{~m} / \mathrm{s}(156 \mathrm{mph}), 6 \mathrm{~m}(20 \mathrm{ft})$. However, this pair will not necessarily include the largest storm surge height occurring during hurricane $h_{i}$. For this reason we include in the data sample a second pair selected as follows. Let that storm surge height be denoted by $s_{i}^{(2)} \equiv \max _{\mathrm{j}}\left(s_{i j}\right)$. The largest of the wind speeds occurring in conjunction with $s_{i}^{(2)}$ is 
denoted by $v_{i}^{(2)}$. The second pair belonging to hurricane $h_{i}$ that is selected for inclusion in the sample is $v_{i}^{(2)}, s_{i}^{(2)}$. Since $i=n$, the total number of pairs in the sample is therefore $2 n$.

The construction of the histograms of wind speeds and storm surge heights, and the estimation of the associated probabilities of exceedance and mean recurrence intervals is similar to those discussed in Section 3.1. The difference is that the epoch inherent in the inverse of the probability of exceedance is half as small as was the case in Section 3.1, owing to the use of two pairs of variates in each hurricane. The advantage of estimates based on sample space SE2 over those based on SE1 is that the pairs of variates represent simultaneous wind speeds and storm surge heights at the site. However, the information yielded by those estimates can be unconservative from a structural engineering point of view, because pairs of variates $v, s$ can exist that are more unfavorable from an engineering viewpoint than the pairs of the type $v_{i}^{(1)}, s_{i}^{(1)}$ and type $v_{i}{ }^{(2)}, s_{i}{ }^{(2)}$. Such unfavorable pairs are not revealed by analyses based on the sample space SE2, owing to the impossibility of rank-ordering between pairs of the type $v_{i}^{(1)}, s_{i}^{(1)}$ the one hand and type $v_{i}^{(2)}, s_{i}^{(2)}$ on the other.

\section{B.2 ESTIMATES CORRESPONDING TO SAMPLE EVENT SPACE SE3}

For each hurricane $h_{i}$, pairs of wind speeds $v_{i j}$ and storm surge heights $s_{i j}$ are available for each time is $t_{j}=j \Delta t$, where the time step $\Delta t=5 \mathrm{~min}$, and $j$ denotes the number of the time interval.

For the time interval $T=55,000$ years the quantities of interest can in principle be estimated as follows. For all $i$ and $j$, create a joint histogram of wind speeds and corresponding storm surge heights by placing each of the pairs $v_{i j}, s_{i j}$ in the bin defined by the coordinates $v_{i j}{ }^{-}$ $\Delta v / 2, v_{i j}+\Delta v / 2, s_{i j}-\Delta s / 2, s_{i j}+\Delta s / 2$, where $v_{i j}$ and $s_{i j}$ are integer multiples of the intervals $\Delta v$ and $\Delta s$, respectively. This joint histogram includes the total number $M$ of pairs of wind speeds and corresponding storm surge heights that occur during the time interval $T$ associated with the $n$ hurricanes $\left(M=m_{1}+m_{2}+\ldots+m_{n}\right.$, and $m_{i}(i=1,2, \ldots, n=19,806)$ is the number of pairs of wind speed/storm surge height data in the $i$ th hurricane). The probability of exceedance of the values $v, s$ can in principle be obtained from the sample of size $M$, and the mean recurrence interval of the pair $v, s$ is then equal to the inverse of that probability, the epoch being in this case $55,000 / M$ years. The mean recurrence interval in years is then obtained via multiplication by the yearly rate of arrival of the event of the pairs of wind speed and storm surge height, that is, by $M / 50,000$.

As an illustration, consider the hypothetical case $m_{1}=m_{2}=\ldots=m_{n} \approx m$, and assume that the duration of all hurricanes within the zone in which they affect the site is 50 hours. The time step in our calculations is assumed to be $\Delta t=5 \mathrm{~min}$, so $m \approx 50$ hours $/(1 / 12$ hour $)=600$, and $M \approx$ $600 n=600 \times 19,806 \approx 12,000,000$. Assuming, for example, that in the histogram $V>120 \mathrm{mph}$ and $S>7 \mathrm{ft}$ for a total number of times equal to 10,000 , we have a probability of exceedance in the interval $T$ denoted by $\operatorname{Prob}_{T}(V>54 \mathrm{~m} / \mathrm{s}(120 \mathrm{mph}), S>2.1 \mathrm{~m}(7 \mathrm{ft}) \approx 10,000 / 12,000,000=$ $1 / 1,200$, and the estimated mean recurrence interval is $\mathrm{MRI}_{\text {epoch }_{T, M}}=1,200$, in epochs of $50,000 / 12,000,000 \mathrm{yr}$, and the estimated mean recurrence interval in years is $\mathrm{MRI}_{\text {years }}=$ $1,200 \times 50,000 / 12,000,000=50$ years. 
The approach just outlined does not take into account the important fact that the pairs $v, s$ within any one of the simulated hurricanes are not independent of each other, but are correlated as they belong to the same hurricane and are separated, within each hurricane, by 5-min intervals. The correlations can significantly affect the results being sought. In principle, knowledge of the cumulative distribution function and of the correlation structure within each hurricane could be used to yield realistic estimates. However, the present state of the art does not allow such estimates to be readily obtained for non-Gaussian bivariate processes such as those representing the simulated time histories of wind speeds and storm surge heights. A considerable research effort would be required for the development of procedures allowing such estimates to be made.

Choosing an interval longer than 5 min might be viewed as eliminating or reducing the severity of the problem just outlined. However, intervals significantly longer than 5 min would result in missing significant peaks. In addition, correlations would subsist even if for longer intervals between successive pairs $v, s$. To avoid the problems associated with correlated data it would be desirable to select, among the pairs $v, s$, only the most significant ones. However, in general it is not possible to do so directly, since no criterion is available for ranking pairs of data in a way that would be satisfactory from an engineering design viewpoint. For example, in some applications the pair $v=36 \mathrm{~m} / \mathrm{s}(80 \mathrm{mph}), s=1.8 \mathrm{~m}(6 \mathrm{ft})$ might be more unfavorable than the pair $v=40 \mathrm{~m} / \mathrm{s}(90 \mathrm{mph}), s=1.5 \mathrm{~m}(5 \mathrm{ft})$, whereas in other applications the reverse could be true. 